\title{
The National Rise in Residential Segregation
}

\author{
Trevon D. Logan and John M. Parman
}

\begin{abstract}
Exploiting complete census manuscript files, we derive a new segregation measure using the racial similarity of next-door neighbors. The fineness of our measure reveals new facts not captured by traditional segregation indices. First, segregation doubled nationally from 1880 to 1940 . Second, contrary to prior estimates, Southern urban areas were the most segregated in the country and remained so over time. Third, increasing segregation in the twentieth century was not strictly driven by urbanization, black migration, or white flight: it resulted from increasing racial sorting at the household level. In all areas-North and South, urban and rural-segregation increased dramatically.
\end{abstract}

$\mathrm{T}$ he importance of residential segregation in explaining modern racial differences in socioeconomic outcomes is well known. There are a variety of studies linking segregation in the United States to schooling and labor market outcomes for African Americans (Kain 1968; Cutler, Glaeser, and Vigdor 1999; Cutler and Glaeser 1997; Collins and Margo 2000). Segregation has also been shown to impact the health of African Americans through a lack of access to health care (Almond, Chay, and Greenstone 2006). Additionally, there is a growing literature on the importance of neighborhood effects and social networks suggesting that segregated neighborhoods could contribute to racial gaps in a variety of socioeconomic outcomes (Case and Katz 1991; Brooks-Gunn et al. 1993; Borjas 1995; Cutler, Glaeser, and Vigdor 2008; Ananat 2011; Ananat and Washington 2009; Echenique and Fryer 2007). It is clear that any explanation of modern racial differences in socioeconomic outcomes must consider the effects of residential segregation on a host of factors.

The Journal of Economic History, Vol. 77, No. 1 (March 2017). (C) The Economic History Association. All rights reserved. doi: 10.1017/S0022050717000079

Trevon D. Logan is Professor, Department of Economics, The Ohio State University and NBER, 1945 N. High Street, 410 Arps Hall, Columbus, OH 43210. E-mail: logan.155@osu.edu. John M. Parman is Assistant Professor, Department of Economics, College of William and Mary and NBER, 254 Tyler Hall, Williamsburg, VA 23187. E-mail: jmparman@wm.edu.

We thank Rodney Andrews, David Blau, Shari Eli, Joe Ferrie, Judge Glock, Daeho Kim, Allison Shertzer, Randall Walsh, Richard Steckel, seminar audiences at Michigan, Occidental, UC-Riverside, UC-Irvine, Yale, American University, Pomona College, UT-Dallas, Virginia Commonwealth University, Dalhousie University, The Ohio State University, ASSA Annual Meetings, and NBER Summer Institute provided welcome suggestions. William D. Biscarri, Nicholas J. Deis, Jackson L. Frazier, Adaeze Okoli, Terry L. Pack, Stephen Prifti and Colin Weinshenker provided excellent research assistance. 
The effects of segregation, however, are not only contemporary but also part of a long-run process of racial sorting which requires historical investigation. Understanding segregation in the decades between the Civil War and the Great Migration is essential to understanding the historical origins of racial gaps in socioeconomic outcomes as well as modern patterns of segregation and discrimination. However, a lack of data essential to estimating traditional measures of segregation has led to few quantitative estimates of segregation prior to the second half of the twentieth century. Given the significant impacts of segregation on outcomes in the modern economy, it would be tremendously valuable to understand how segregation patterns evolved and influenced outcomes in the period between Reconstruction and the Great Migration, a period during which blacks became a predominately urban group and a period that ushered in Jim Crow laws and other racially-restrictive codes, institutionalizing segregation. A broad, long-run view of segregation that encompasses both urban and rural areas is required if we are to understand its function and change over time.

A comprehensive measure of segregation is also an important empirical element in a growing literature seeking to analyze the institutional development of the United States. While regional income differences are well known, scholars have found strong evidence in support of the persistence of regional-specific institutions on a range of economic outcomes (Naidu 2012; Alston and Ferrie 1993; Wright 1986; Margo 1990; Hornbeck and Naidu 2014; Ramcharan 2010). The effects of these institutional developments have important implications for the residential living patterns of black and white residents in urban and rural communities.

To date, however, we do not know how historical residential segregation in rural communities impacted racial gaps in outcomes or how it related to institutional developments given the focus of existing empirical studies of historical segregation on urban areas. David Cutler, Edward Glaeser, and Jacob Vigdor (1999) document changes in urban residential patterns over the entire twentieth century. Allison Shertzer and Randall Walsh (2016) further examine the 1900 to 1930 period using neighborhood-level data for ten major cities while William Collins and Robert Margo (2000) provide further analysis of changing urban residential patterns from 1940 to 1990 . These studies find that urban segregation rose drastically over the twentieth century as blacks migrated to cities and then became concentrated in city centers as white residents moved to suburbs. However, these studies utilize traditional segregation measures that are specific to cities. These measures compare the racial composition of wards within a city to the racial composition of the city as a whole and are not well-suited to rural areas that lack equivalent geographic subunits. 
Consequently, there is little quantitative evidence of segregation and its effects prior to the Great Migration when the black population was still a primarily rural population. Between 1870 and 1940, the share of the black population living in rural areas fell from roughly 90 percent to under 50 percent. There are few theoretical reasons to believe that segregation in these rural communities is unimportant or unrelated to socioeconomic outcomes (Lichter et al. 2007). Furthermore, the segregation patterns in the rural communities that black residents left may be a crucial piece to understanding the causes and consequences of the Great Migration.

In an effort to allow for a more comprehensive analysis of segregation, this article introduces a new measure of residential segregation. Our measure uses the newly available complete manuscript pages of the 1880 and 1940 federal censuses to identify the races of nearby neighbors. We measure segregation by comparing the number of households in an area living next to neighbors of a different race to the expected number under complete segregation and under no segregation (random assignment). The resulting statistic provides a measure of how much residents segregate themselves given the particular racial composition of the area. The measure allows us to distinguish between the effects of differences in racial composition and the tendency to segregate given a particular racial composition. By exploiting actual residential living patterns of individual households, this measure is equally applicable to rural and urban areas and can be consistently applied over time. Previous advances in the measurement of segregation have attempted to use smaller geographic units (Reardon and O'Sullivan 2004; Echenique and Fryer 2007; Reardon et al. 2008), but none has comprehensively exploited the actual pattern of individual household location as we do here nor have they been extended to rural communities. Our measure is the first to give a complete picture of segregation for the entire United States and does so at the finest level of detail possible for residential location. For an understanding of the evolution of racially distinct residential living patterns and for uncovering the root causes of changes in segregation, the dimension of segregation captured by this new measure is essential.

Our neighbor-based measure establishes several new facts about segregation in the United States. First, we find that segregation, as measured by our neighbor-based index, doubled nationally from 1880 to 1940 . This is the first evidence of a national increase in segregation. Second, contrary to previous estimates which implied that Northern cities were the most segregated areas (Cutler, Glaeser, and Vigdor 1999), we find that cities in the South were the most segregated in the country and remained so over time. While blacks and whites occupied the same wards and districts in Southern cities, they were the least likely to be neighbors. This finding 
is a direct result of a measure of segregation that builds from individual household position as opposed to ward population shares. Third, we find that increasing segregation over time was not confined to cities, was not driven by black migratory patterns, nor was urbanization the sole driving force behind increasing segregation. Our neighbor-based measure of segregation shows that population sorting by race changed just as dramatically in rural areas as in urban areas. The broad, national increase in racial sorting we document is a new historical fact that alters the existing segregation narrative that depends critically on African American migratory flows and points to a more general trend in residential racial separation than has been previously suggested.

These results suggest that the traditional story of increasing segregation in urban areas in response to black migration to urban centers must be augmented with a discussion of the contemporaneous increasing racial segregation of rural areas. Both rural and urban areas in every region experienced marked increases in segregation. Our findings show that the likelihood of opposite-race neighbors declined precipitously in every region in the United States. Our findings complicate traditional explanations of blacks clustering in small areas abutting white communities (Kellogg 1977), and of racial segregation being driven by restrictive covenants (Gotham 2000), as both of these were urban phenomena. The increase in rural segregation also challenges historical narratives which view population dynamics in rural areas as stagnant. The focus on urban segregation has neglected the fact that rural areas were segregated and, as we have discovered, became increasingly segregated over time. While there are studies which seek to look at the causal effect of black social networks in rural areas on outcomes (Chay and Munshi 2013), they use county racial proportions which we show are relatively poorly correlated with residential segregation. Overall, the national trend in increasing segregation through the middle of the twentieth century adds a new chapter to American history and shows that patterns of racial sorting were quite general over time.

\section{A NEIGHBOR-BASED MEASURE OF SEGREGATION}

We begin with a brief overview of existing segregation measures and use that discussion to motivate the usefulness of our new approach to segregation. In particular, the limited applicability of the most widelyused measures of segregation to non-urban areas creates a problem when attempting to describe the broad change in racial residential segregation which is our task here. 


\section{The Limitations of Traditional Segregation Measures}

A wide range of measures have been introduced to measure segregation. Douglas Massey and Nancy Denton (1988) provide an overview of 20 different measures in use in the segregation literature. These various measures all capture different dimensions of segregation. Massey and Denton broadly categorize these as centralization, concentration, exposure, evenness, and clustering. The majority of the segregation literature has focused on the dimensions of evenness and exposure; the two dimensions of segregation economists have held as most important in determining how segregation influences socioeconomic outcomes.

Evenness is the differential distribution of social groups across geographic subunits. As evenness decreases it becomes more likely that minorities have significantly different access to schooling and health resources as well as labor markets due to their concentration in specific subunits. Exposure measures the degree of potential contact between social groups. To the extent that social networks and peer effects are important for outcomes, differences in the levels of exposure will have potentially significant consequences for groups excluded from such networks due to limited contact. The economics literature on segregation has typically relied on two specific measures of these dimensions: the index of dissimilarity as a measure of evenness and the index of isolation as a measure of exposure.

The index of dissimilarity is a measure of how similar the distribution of minority residents among geographical units is to the distribution of non-minority residents among those same units. ${ }^{1}$ The index compares the percentage of the overall black population living in each geographical subunit to the percentage of white residents living in that same area. The index of isolation provides a measure of the exposure of minority residents to other individuals outside of their group. ${ }^{2}$ This is a measure

\footnotetext{
${ }^{1}$ Formally, if $i$ is an index for the $N$ census tracts within a city, $B_{i}$ is the number of black residents in tract $i, B_{\text {total }}$ is the total number of black residents in the city, $W_{i}$ is the number of white residents in tract $i$, and $W_{\text {total }}$ is the total number of white residents, the index of dissimilarity for the city is:
}

$$
\text { Dissimilarity }=\frac{1}{2} \sum_{i}^{N}\left|\frac{B_{i}}{B_{\text {total }}}-\frac{W_{i}}{W_{\text {total }}}\right| .
$$

${ }^{2}$ Using the same notation, the index of isolation for a city is given by:

$$
\text { Isolation }=\sum_{i}^{N}\left(\frac{B_{i}}{B_{\text {total }}} \cdot \frac{B_{i}}{B_{i}+W_{i}}\right)
$$


of the racial composition of the geographical unit for the average black resident, where racial composition is measured as the percentage of the residents in the unit who are black.

While Cutler, Glaeser, and Vigdor (1999) and Werner Troesken (2002) demonstrate that these traditional measures of segregation can be applied to historical data, their studies also highlight the limitations of measures of isolation and dissimilarity when applied to the early 1900s. Chief among these limitations are the measures' data requirements. Estimation of either index requires observing variation in the racial composition of the geographical subunits making up the larger geographical unit of interest. Cities have a somewhat natural subunit of wards or, in more recent decades, census tracts. Rural counties do not necessarily have a comparable subunit. The index of dissimilarity and the index of isolation therefore allow us to understand historical levels of segregation in cities but not in the areas surrounding those cities or in rural counties. This presents a severe limitation on our understanding of segregation in the past when the majority of individuals, and particularly black individuals, lived in rural areas. The index of isolation and index of dissimilarity can tell us how segregation in cities changed with the influx of these individuals but they cannot tell us how segregation in the rural counties contributed to that migration and changed as a result of it.

An additional problem with these traditional measures is that they only use population shares within a given geographic subunit, obscuring within-area segregation and making them poor proxies for social interactions, social networks, and interpersonal exchange. This is particularly problematic for rural areas where geographical subunits may be less meaningful proxies for social interactions. ${ }^{3}$ Furthermore, if the size of these geographical subunits or the economic implications of living in a particular subunit differ across rural and urban communities, it becomes difficult to make meaningful comparisons of the traditional segregation indices between rural and urban areas.

There is a final critique of using these traditional measures that has special importance when considering the history and evolution of segregation. Federico Echenique and Roland Fryer (2007) and Barrett Lee et al. (2008) note that these measures are highly dependent on the way

\footnotetext{
${ }^{3}$ Rhode and Strumpf (2003) analyze inequality in rural counties, but they do not calculate traditional segregation measures for all counties. Lichter et al. (2007) calculate dissimilarity for rural areas using 1990 and 2000 census data using census blocks. They find that the pattern of segregation in rural communities is very similar to the pattern in urban communities, with African Americans the most segregated racial group in both rural and urban areas. They note that the highly aggregated nature of the census block in rural communities limits their ability to speak to the forces shaping the segregation patterns.
} 
the boundaries of the geographical subunits are drawn. The measures are sensitive to the number of geographic subunits used, the way the boundaries for those subunits are drawn, and small changes in the distribution of people across those subunits when they contain small numbers of minority residents. These are issues that Cutler, Glaeser, and Vigdor must deal within estimating city segregation when the available data switches from ward-level data to census tract-level data in 1950. In the cases where Cutler, Glaeser, and Vigdor have data at both the ward and census tract levels, the correlation between the index of dissimilarity for Southern cities using wards and the same index using census tracts is only $0.59-0.35$ with one outlier removed.

What makes this particularly problematic for measuring historical segregation patterns is that political motivations when drawing ward boundaries can have dramatic effects on segregation measures and the inference we draw from them. A city in which wards are drawn to minimize the voting power of black residents by dispersing their votes across wards may appear to be highly integrated. If the same city had wards drawn to make it easier to discriminate in the provision of public services by placing black residents in a small number of wards it would appear completely segregated (see Rabinowitz (1996), for examples of gerrymandering in American cities). The endogenous nature of political boundaries makes it difficult to analyze segregation as the cause or consequence of institutional development using traditional measures. Regardless of the motivations for drawing boundaries, existing measures tell us little about proximity or sorting within any boundary, arbitrary or not.

In an Online Appendix, we simulate completely integrated and completely segregated areas, varying the size of the black population and the number and location of subunit boundaries and estimate dissimilarity, isolation, and our neighbor-based measure. These simulations demonstrate the sensitivity of traditional measures to the number of boundaries used and how those boundaries are drawn. Confidence intervals are as large as 0.2 units for the dissimilarity index and 0.5 units for the isolation index for the completely segregated areas, substantially larger than the empirical standard deviation of these measures across counties. In the case of perfectly integrated areas, both the isolation index and the dissimilarity index are significantly larger than zero when the black population is small (under 50 black households in an area of 2,000 households total). These simulations confirm the limitations of using traditional measures to capture historical segregation, particularly for small black populations and rural areas. 


\section{A Neighbor-Based Measure of Segregation: Advantages and Limitations}

Our measure provides an intuitive approach to quantifying residential segregation that avoids the pitfalls of traditional measures. We use the location of households in adjacent units in census enumeration to measure the degree of integration or segregation in a community, similar to Schelling's classic model of household alignment. At its core, the Schelling model of segregation is based on next-door neighbors. ${ }^{4}$ Nextdoor neighbors are also the focus of surveys on preferences about racial integration (see, for example, Bobo and Zubrinsky (1996), Zubrinsky and Bobo (1996), and Farley, Fielding, and Krysan (1997)). ${ }^{5}$ By looking at the races of next-door neighbors rather than racial proportions, we ask a fundamentally different question about segregation than traditional measures, one that aligns more closely to existing models of segregation and the intuition of residential segregation. Areas that are well integrated will have a greater likelihood of opposite-race neighbors corresponding to the underlying racial proportion of households in the area. The opposite is also true - segregated areas will have a lower likelihood of opposite-race neighbors than racial proportions would predict.

This measure uses census enumeration ordering of households to define neighbors, exploiting the fact that adjacent households appear next to each other on the census manuscript page. This is a one-dimensional approach to neighbors given the limitations of the data; the census manuscript pages do not identify neighbors living behind or across the street from a household. Whether one has an opposite-race neighbor across the street or across a back alley, however, is highly correlated with the segregation of the community.

Our approach has additional compelling features. First, we focus on households as opposed to the population. ${ }^{6}$ If members of one group have larger household sizes or different household structure (as was the case historically, Ruggles et al. (2009)) there will be a difference between the population share and the household share. Another advantage is that

\footnotetext{
${ }^{4}$ In the classic formulation, segregation is the product of household preferences over the race of their neighbor and their neighbor's neighbor (Schelling 1969, 1971). For a model which includes preferences over schools see Bayer, Ferreira, and McMillian (2007). For a recent example of a test of Schelling's tipping model see Card et al. (2008).

${ }^{5}$ Studies such as Clark (1991) ask respondents about racial proportions, but these are rare.

${ }^{6}$ Grigoryeva and Ruef (2015) build on the method of Agresti (1980) and calculate a sequenced index of segregation that counts "runs" (sequences) of households by race. Like traditional measures of segregation, the sequenced index of segregation is applied only to urban areas. While related to our measure, their measure requires the strong assumption that the entire enumeration district was surveyed in a linear fashion.
} 
this measure is an intuitive proxy for social interactions at the extensive margin. Neighbors are quite likely to have some sustained interactions with each other; an increasing likelihood of opposite-race neighbors implies that the average level of interactions across racial lines would be higher. ${ }^{7}$ Social interaction models of segregation are inherently spatial and assume that close proximity is related to social interactions both directly and indirectly (Echenique and Fryer 2007; Reardon et al. 2008). Our next-door neighbor approach guarantees this proximity, whereas relying on population shares in geographical subunits such as wards does not. Lastly, our measure can distinguish between areas with similar racial proportions but different tendencies to sort within areas on the basis of race.

The neighbor-based measure is no panacea, however. The focus on individual households, while useful for considering social interactions, is less helpful for considering public goods provision, voting patterns, school district quality, and other outcomes for which ward boundaries are highly relevant. If social networks and exposure to other racial groups are of interest, the neighbor-based measure is useful but still falls short of an ideal measure which would capture a fuller range of social interactions. The measure focuses only on next-door neighbors and the nearest neighbor. While the measure could be extended in theory to encompass larger sets of neighbors, in practice the ability to do so is limited by the available data. Another issue is that the measure treats next-door neighbors the same whether they are near or far from the household of interest. While distance between neighbors is important for understanding the strength of social interactions, incorporating that information requires each household to have a geocoded address, something not available in historical census data. Finally, the focus on household location to capture the likelihood of social interactions ignores interracial social interactions that occur through other channels and which may be unrelated to residential location.

\section{Next Door Neighbors and Census Enumeration}

Census enumerators went door-to-door to survey households until 1960, when the Census Bureau first began mailing questionnaires. The position on the manuscript census form therefore provides a measure of

\footnotetext{
${ }^{7}$ Even in the Jim Crow South, where social interactions between races may have been quite limited even with close physical proximity, closer physical proximity will still imply greater exposure at the household level to opposite-race neighbors which could strongly influence attitudes toward other racial groups (Carrell, Hoekstra, and West 2015; Williams, Jr. 1947).
} 
the actual location and composition of households as one would "walk down the street" from residence to residence. Proximity in the manuscript census form is, by design, a measure of residential proximity because enumeration was recorded in sequenced order.

Our assumption is that households adjacent on the manuscript page are next-door neighbors. For this to hold, two conditions are necessary. First, census enumerators must visit every household. Second, they must visit those households in the order in which they are physically situated. There are several historical facts supporting the first condition of complete enumeration (Magnuson and King 1995; Grigoryeva and Ruef 2015; Agresti 1980). Official training of enumerators specifically required an accurate accounting of dwellings containing persons in order of enumeration; a personal visit to each household was required. Enumeration instructions directed enumerators to obtain information on households who could not be surveyed from "the family or families, or person or persons, living nearest to such place of abode" (U.S. Department of the Interior 1880). The completeness of the enumeration was further ensured by the public posting of each enumeration for several days for public comment and correction and by being cross-checked with external sources such as voting records and other municipal information. Accuracy of the records had to be ascertained before the enumerator received payment.

The door-to-door nature of these personal visits to each household and the ability to obtain information for missing households from neighbors suggests that the second condition, that households are recorded in the order in which they are physically situated, also holds. Angelina Grigoryeva and Martin Ruef (2015) provide confirmation of this assessment, documenting that the census enumeration of Washington, DC in 1880 followed an ordered process in which the enumerator moved between adjacent households facing the same street. However, the linear path cannot be verified for other locations due to data limitations and the incomplete records pertaining to the specifics of enumeration in each locality. Census enumeration does not typically contain addresses, even for urban areas. In general, however, the policies and procedures of enumeration since 1880 give us confidence that our approach is the best available proxy for household adjacency.

An obvious concern for rural communities would be the distance between neighbors identified in census manuscript files. If distance plays a role in the likelihood of opposite race neighbors we would expect significant differences in the level and change of segregation in rural communities relative to urban ones. However, one should not overstate 
the expected differences between urban and rural areas with respect to segregation. First, the nearest neighbor is still the nearest. Since enumeration districts were quite compact, even for rural areas, these adjacent households were closer than one may be led to believe. Those at quite a distance would be placed in a different enumeration district for practical purposes of efficient enumeration. Furthermore, the typical farm is relatively small. In 1880, 29 percent of farms were under 50 acres, less than 0.3 miles wide, putting adjacent farmers within walking distance from each other. More than 50 percent were under 100 acres, less than 0.4 miles on each side. By 1940, 38 percent of farms were under 50 acres while 59 percent were under 100 acres (Department of Commerce 1943, Table 15). Another important consideration is that African Americans were far less likely to be landowners and, if landowners, owned smaller farms. As such, they would be less distant from their opposite race neighbors. Differences in land ownership greatly impacted the residential location of the average African American family-they were usually not living on independent farms but rather more likely to live in compact tenant farming communities (Litwack 1998; Ransom and Sutch 2001).

It is also important to note that rural communities had recognized neighborhoods. Any town smaller than 2,500 residents or any town that was unincorporated was considered rural by census definitions, leading to many communities with distinct neighborhoods falling under the rural designation. The federal government used rural neighborhood location and ethnic population shares in determining farm value in early twentieth century mortgage underwriting, which implies that neighborhoods were clearly defined in rural communities and that their racial and ethnic distributions were important. These criteria date back to Federal Land Banks, established by the Federal Farm Loan Act of 1916. In the Senate investigations of European farm credit systems leading up to the Federal Farm Loan Act, investigators noted the importance of homogeneity among people in European farming neighborhoods as a key feature of getting land banks to function, expressing concern over the racial and ethnic heterogeneity of American farming neighborhoods (see, for example, discussion of German versus American farm communities in U.S. Senate Committee on Banking and Currency (1914) and McMillan (1916)). ${ }^{8}$ Similarly, John Parman (2012) shows that human capital spillovers

\footnotetext{
${ }^{8}$ Underwriters on farm loans were even encouraged to, "get frank information in the farmer's neighborhood concerning the borrower as a man and as a farmer," underscoring the importance of social networks in farming communities and reinforcing the notion that neighborhoods existed within rural areas (Taylor 1915, p. 726).
} 
worked through neighboring farms in early-twentieth-century Iowa and varied in strength depending on whether adjacent farmers shared a common religious or ethnic background, suggesting that interactions in sparsely populated areas are significant and have a measurable economic impact. ${ }^{9}$ In short, living in a rural community with less dense population did not necessarily imply that neighbors were excessively distant from one another nor that social and economic interactions between neighbors were any less important than in urban areas.

\section{Deriving the Segregation Measure}

Construction of the measure begins by identifying neighbors in manuscript census records. ${ }^{10}$ Our method requires the complete, 100 percent census since all households are needed. The complete set of household heads in the census is sorted by reel number, microfilm sequence number, page number, and line number. This orders the household heads by the order in which they appear on the original census manuscript pages, meaning that next-door neighbors typically appear next to one another. Institutions, boarding houses and other non-households (dormitories, etc.) are excluded from the calculation. Households in apartments or other multi-family units are recorded as separate households in the census and are retained. Domestic servants living with their employers were listed as servants in the census rather than household heads and are therefore not included as separate households. We focus our analysis on black households, assessing whether they have a neighbor of a different race. All racial groups other than blacks or whites constituted less than 0.5 percent of the total population from 1870 to 1940 in census returns. As such, a black household with a neighbor of a different race is equivalent to saying they have a white neighbor. ${ }^{11}$ Given the extremely low levels of interracial marriage in the past (fewer than 0.2 percent of households had opposite race spouses from 1870 to 1940), we assume the race of the household head applies to all household members.

We define the next-door neighbors as the households appearing before and after the individual on the census manuscript page. An individual

\footnotetext{
${ }^{9}$ The mean farm size in this study was 153 acres, similar to the mean farm size for the country as a whole suggesting that the experience of Iowa in terms of interactions between rural residents would be applicable to other rural areas in the United States.

${ }^{10}$ The full derivation of the segregation measure is given in the Online Appendix.

${ }^{11}$ For our purposes people with their race given as "mulatto" are considered to be in the same category as people with their race given as "black."
} 
that is either the first or last household head on a particular census page will only have one next-door neighbor identified using this method. To allow for the next-door neighbor appearing on either the previous or next census page and to account for the possibility that two different streets are covered on the same census manuscript page, an alternative method for identifying neighbors is to look at the observations directly before and after the household in question and declare them next-door neighbors if and only if the street name matches the street name of the individual of interest. While this alternative approach has the advantage of finding the last household on the previous page if an individual is the first household on his census manuscript page (or the first household on the next page if the individual was the last household on a manuscript page), the number of observations is reduced substantially relative to the first method as the majority of individuals have no street name given in the manuscript census files. For this reason, the results presented in this article use the first method of identifying neighbors. ${ }^{12}$

Once next-door neighbors are identified, we construct an indicator variable that equals one if the individual has a next-door neighbor of a different race and zero if all observed next-door neighbors are of the same race as the household. As such, the measure of opposite-race neighbors is measured at the extensive margin. Summing this indicator variable across all black households for the entire county gives us the number of black households with a next-door neighbor of the opposite race, $x_{b}$. The segregation measure compares this number of black households with opposite-race neighbors to the expected number under complete segregation, $E\left(x_{b}\right)$, and the expected number under complete integration (random assignment of neighbors), $E\left(\overline{x_{b}}\right) \cdot{ }^{13}$ These two values are calculated based on the total number of black households and white households in a county. $E\left(x_{b}\right)$ is calculated assuming that only the two households on either end of the black neighborhood, in other words the first and last black households appearing on the census manuscript pages,

\footnotetext{
${ }^{12}$ Results using the second, street name-based method are available upon request.

${ }^{13}$ We take random assignment of neighbors by race as our benchmark for a completely unsegregated area as we are primarily interested in whether people are self segregating. However, an area could be more integrated than this if you alternated households by race to maximize the number of black households with white neighbors. This benchmark may be more relevant if considering policies specifically designed to promote integration. We discuss this alternative approach in the derivation section of the appendix and provide a comparison of estimates using the benchmark of random assignment and the benchmark of maximum integration. Segregation levels are slightly higher under the latter benchmark but all of the patterns discussed in our results remain unchanged.
} 
have white neighbors. ${ }^{14} E\left(\overline{x_{b}}\right)$ is calculated assuming that households are randomly assigned by race: the probability of a next-door neighbor being of the opposite race is given by the fraction of the households in the county of that race. ${ }^{15}$

The degree of segregation in an area is defined as the distance between these two extremes, measured from the case of no segregation:

$$
\eta=\frac{E\left(\overline{x_{b}}\right)-x_{b}}{E\left(\overline{x_{b}}\right)-E\left(\underline{x_{b}}\right)} .
$$

This segregation measure increases as black residents become more segregated within an area. The measure equals zero in the case of random assignment of neighbors (no segregation) and equals one in the case of complete segregation. The measure is only defined for racially heterogeneous communities, as racially homogeneous communities are neither segregated nor integrated. The segregation measure is normalized by the population size and the percent of African Americans in the community, which allows for comparison of segregation across communities with different population sizes and racial compositions.

We have derived the segregation measure for analysis of neighbors situated along a line in order to match the way in which neighbors can be identified in the census manuscript pages. However, it should be noted that the measure can be easily extended to considering two-dimensional residential patterns rather than simply household sequences along a line. Expanding the definition of next-door neighbors to include those living behind a household or across the street from the household simply requires adjusting the probability terms in the definition of $E\left(\overline{x_{b}}\right)$ to account for the probability that any one of the four next-door neighbors is white and adjusting $E\left(\underline{x_{b}}\right)$ to account for all of the black households

\footnotetext{
${ }^{14}$ This value is a function of the probability of observing one or both of the two black households with white neighbors (a non-trivial number of households in the census do not have legible races given for their neighbors). Defining the number of black households with both neighbors' races observed as $n_{b}$ and the total number of black households in the county as $b_{\text {all }}$, the value of $E\left(x_{b}\right)$ is calculated as $\frac{1}{\frac{1}{2}\left(n_{b}+1\right)}\left(1-\prod_{i=0}^{n_{b}-1} \frac{b_{\text {all }}-i-2}{b_{\text {all }}-i}\right)+2\left(1-\frac{1}{\frac{1}{2}\left(n_{b}+1\right)}\right)\left(1-\prod_{i=0}^{n_{b}-1} \frac{b_{\text {all }}-i-2}{b_{\text {all }}-i}\right)$. In the case of including households with only one observed neighbor, this equation must be modified somewhat to account for the possibility of observing one of the black households with a white neighbor but not observing the white neighbor. Full details are provided in the appendix.

15 Following the same notation as the previous footnote and defining the total number of white households in the county as $w_{\text {all }}$, the value of $E\left(\bar{x}_{b}\right)$ is calculated as $n_{b}\left(1-\frac{b_{\text {all }}-1}{b_{\text {all }}-1+w_{\text {all }}} \cdot \frac{b_{\text {all }}-2}{b_{\text {all }}-2+w_{\text {all }}}\right)$. As with $E\left(\underline{x_{b}}\right)$, the equation must be modified when including households with only one observed neighbor. Details are provided in the Online Appendix.
} 
on the perimeter of the two-dimensional black neighborhood having white neighbors rather than simply the two households on the ends of the one-dimensional neighborhood. This highlights the advantages of constructing a household-level measure of segregation; unlike traditional segregation measures based on geographic subunits or runs in the sequence of households, our measure can accommodate any definition of next-door neighbors fully exploiting available information on household location. While existing federal census information limits us to considering neighbors to the right and left of a household, our measure can accommodate less restrictive definitions of next-door neighbors as richer household-level spatial data become available.

\section{EMPIRICAL COMPARISON OF SEGREGATION MEASURES IN 1880}

\section{County-Level Measures}

We begin with estimates of the segregation measure using the 100 percent sample of the 1880 U.S. federal census. ${ }^{16}$ The next section will examine changes in segregation from 1880 to 1940 , the most recent publicly available complete count census data. The geographic unit of analysis of primary interest is the county. Counties allow us to analyze the differences in segregation between urban and rural areas. They are well-defined civil jurisdictions and a wealth of additional information is available at the county level. ${ }^{17}$ For comparison purposes for both urban and rural counties, we calculate the index of dissimilarity and the index of isolation for all counties. To our knowledge, this produces the first estimates of dissimilarity and isolation for every county in the United States.

As noted earlier, dissimilarity and isolation are typically calculated only at the city level using wards as the geographic subunit for the calculation. Given that rural areas lack wards, we instead use the census enumeration district as the subunit. The enumeration district is typically a smaller unit in terms of population than a ward but still contains

\footnotetext{
${ }^{16}$ The 1880 federal census is the first to use professional enumerators and also has the advantage of being the only federal census to have a fully cleaned and coded 100 percent sample available through the Integrated Public Use Microdata Series.

${ }^{17}$ Note that the urban-rural designation in the federal census is not done at the county level. Counties can include both individuals living in urban places and living in rural places. We designate a county as urban if more than one-quarter of the households from that county live in an urban area and rural if less than one-quarter of the households live in an urban area. Our city-level estimates suggest that the patterns we observe for urban counties are indeed being driven by the individuals residing in the urban areas of those counties.
} 
several hundred households, on average. ${ }^{18}$ The mean rural enumeration district in the 1880 census contains 350 households while the mean urban enumeration district contains 450 households. The mean number of enumeration districts in a rural county is 10 while the mean for urban counties is 39. A key advantage of enumeration districts is that they were designed to maintain the boundaries of civil divisions (towns, election districts, wards, precincts, etc.). The use of enumeration districts helps guard against finding differences between the measures that are simply the product of a higher level of aggregation (calculating dissimilarity and isolation over a larger area) as opposed to actual differences in living arrangements by race.

Figure 1 depicts the variation in our segregation measure and the traditional measures for both rural and urban counties across regions. ${ }^{19}$ The figure depicts the means and ranges of the measures with the end points of the range being one standard deviation above and below the mean. When calculating the means and standard deviations, counties are weighted by the number of black household heads to provide a more accurate picture of the experience of the typical black household and to minimize the effects of outlier counties with few black households. This figure and subsequent maps exclude the mountain and pacific regions, as their populations are less than 1 percent black.

The figure reveals a substantial amount of heterogeneity in segregation within regions, across regions and between urban and rural areas. However, the data also reveal that the patterns of segregation depend heavily on the chosen measure of segregation. To get a better sense of how the measures relate to one another, correlations between the measures are provided in Table 1. Our neighbor-based measure is positively correlated with the percentage of households who are black and with the index of isolation in urban counties. Surprisingly, our measure is negatively correlated with the index of dissimilarity for both rural and urban counties and with isolation in rural counties. However, after weighting by the number

\footnotetext{
${ }^{18}$ An enumeration district is actually more comparable in size to a census block, the geographical subunit used by Echenique and Fryer (2007), than a ward or census tract. Enumeration districts averaged roughly 1,500 persons in 1880 . Since enumeration districts are typically smaller than wards, our estimates of dissimilarity and isolation in urban counties will tend to be higher than those of Cutler, Glaeser, and Vigdor (1999) and Troesken (2002).

${ }^{19}$ To make the sample used for calculating the index of isolation and the index of dissimilarity comparable to the sample used in the calculation of our segregation measure, we drop all household heads for which race is not observed and neighbor's race is not observed. When calculating the index of isolation, we follow the approach of Cutler, Glaeser, and Vigdor (1999) and rescale the isolation index by subtracting the percent black for the county and then normalize the statistic by dividing by the maximum theoretical value of this rescaled isolation index for the county, resulting in an index that is normalized to range between zero and one and is independent of the overall size of the black population.
} 
(a)

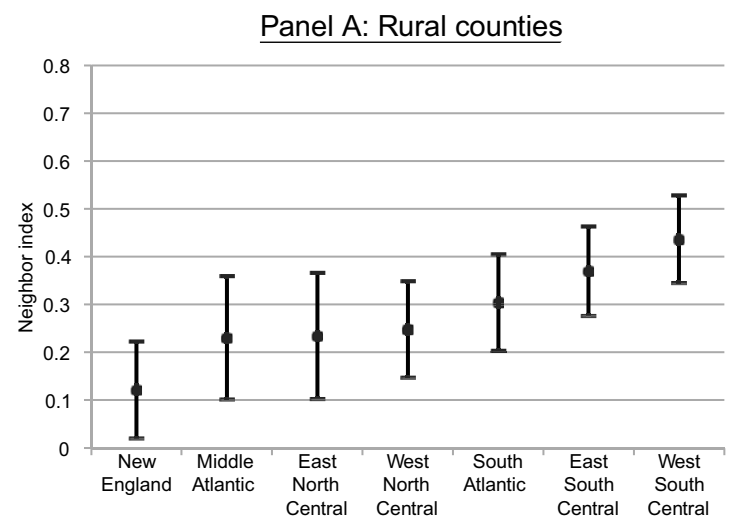

(b)

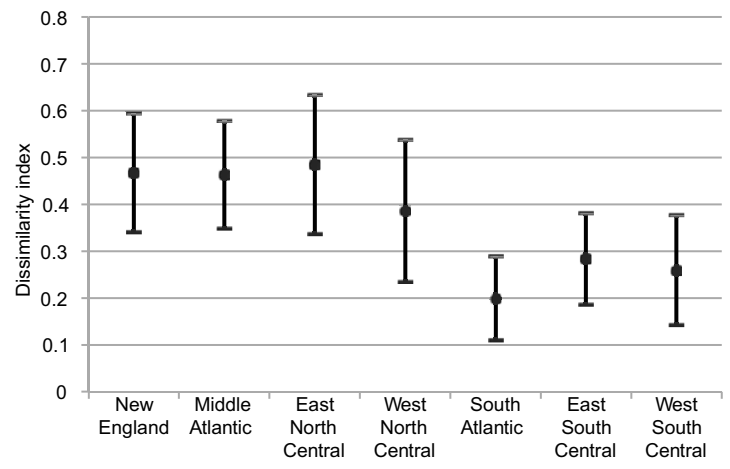

(c)

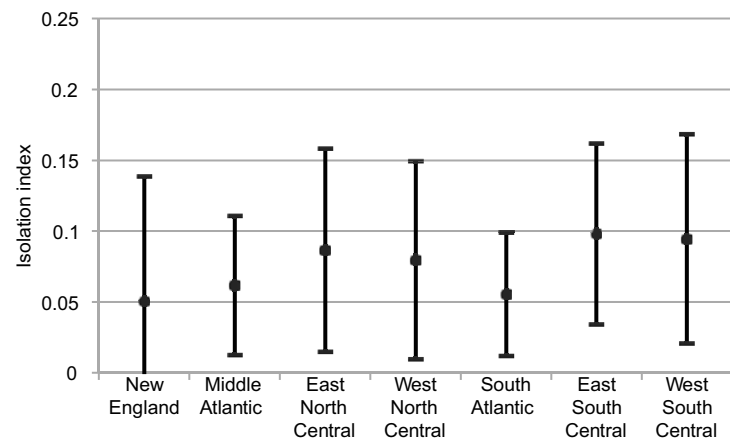

(d)

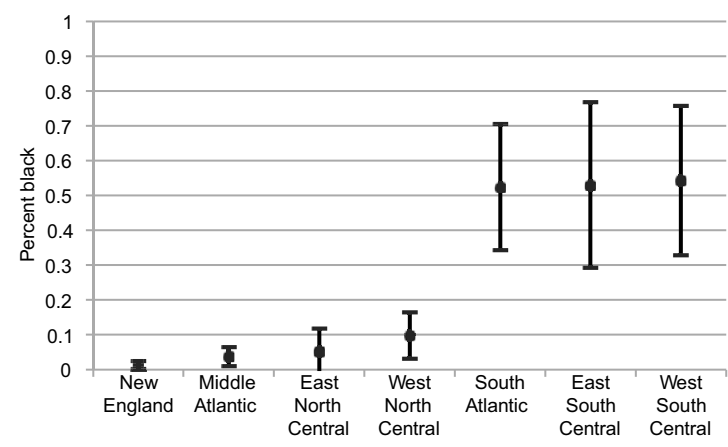

FIGURE 1 


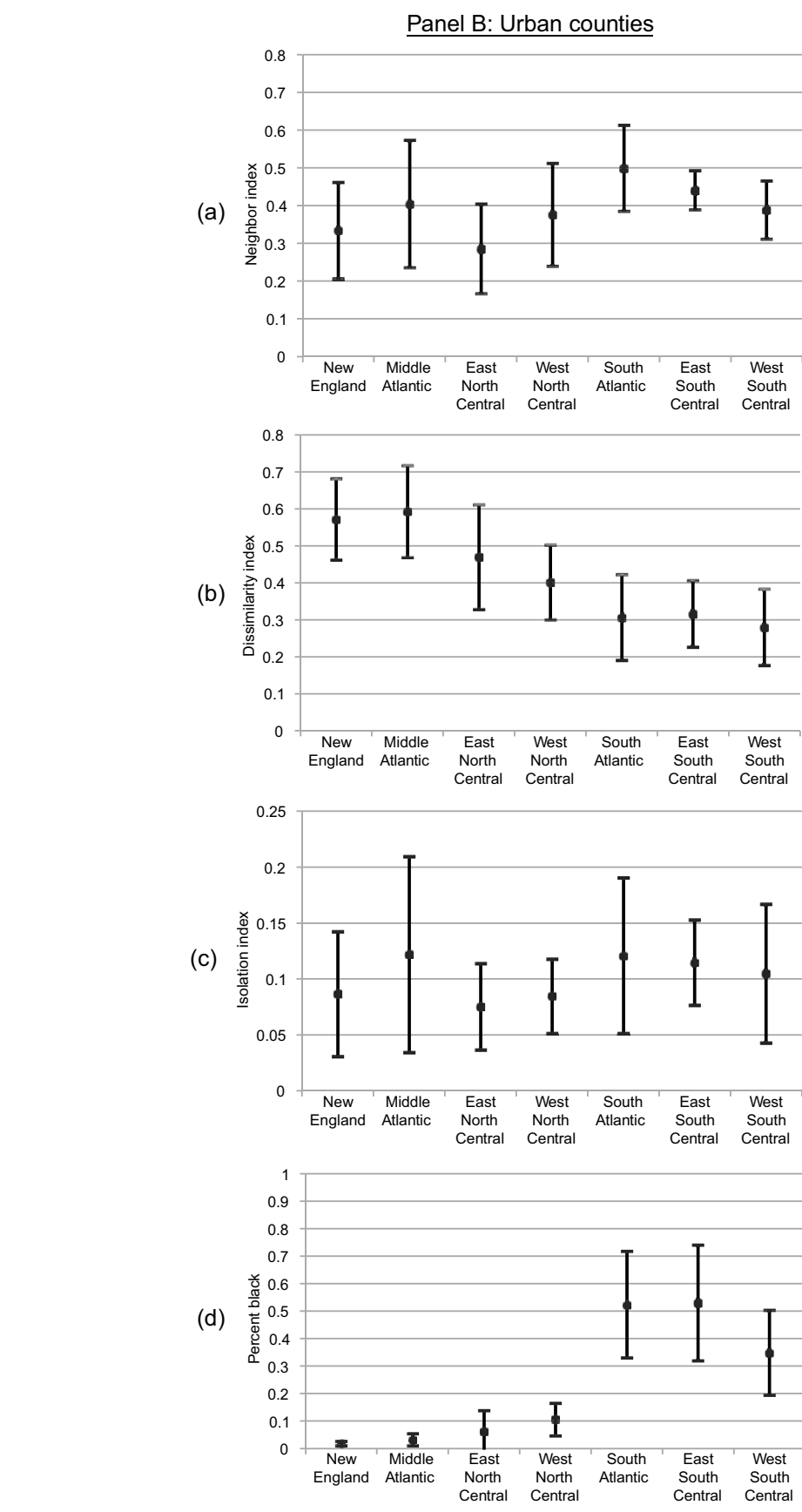

\section{FIGURE 1 (CONTINUED) \\ BLACK HOUSEHOLD-WEIGHTED MEASURES OF SEGREGATION FOR URBAN COUNTIES BY REGION (PANEL B)}

Notes: Upper and lower endpoints of bars correspond to one standard deviation above and below the mean, respectively. The measures in each panel are: (a) our neighbor-based measure, (b) the index of dissimilarlity, (c) the index of isolation, and (d) the percentage of household heads who are black. Source: Authors' calculations based on the IPUMS 100 percent sample of the 1880 federal census. 
TABLE 1

CORRELATIONS IN SEGREGATION MEASURES FOR RURAL AND URBAN COUNTIES, 1880

\begin{tabular}{|c|c|c|c|c|c|c|c|c|c|}
\hline \multicolumn{10}{|c|}{ Rural Counties } \\
\hline & \multicolumn{4}{|c|}{ Unweighted } & & \multicolumn{4}{|c|}{ Weighted by Number of Black Households } \\
\hline & $\begin{array}{l}\text { Neighbor- } \\
\text { Based } \\
\text { Segregation }\end{array}$ & $\begin{array}{c}\text { Percent } \\
\text { Black }\end{array}$ & Dissimilarity & Isolation & & $\begin{array}{l}\text { Neighbor- } \\
\text { Based } \\
\text { Segregation }\end{array}$ & $\begin{array}{l}\text { Percent } \\
\text { Black }\end{array}$ & Dissimilarity & Isolation \\
\hline Neighbor-based segregation & 1 & & & & Neighbor-based segregation & 1 & & & \\
\hline Percent black & 0.61 & 1 & & & Percent black & 0.43 & 1 & & \\
\hline Dissimilarity & -0.36 & -0.5199 & 1 & & Dissimilarity & 0.29 & -0.21 & 1 & \\
\hline Isolation & -0.02 & -0.16 & 0.53 & 1 & Isolation & 0.55 & 0.08 & 0.76 & 1 \\
\hline \multicolumn{10}{|c|}{ Urban Counties } \\
\hline & \multicolumn{4}{|c|}{ Unweighted } & & \multicolumn{4}{|c|}{ Weighted by Number of Black Households } \\
\hline & $\begin{array}{l}\text { Neighbor- } \\
\text { Based } \\
\text { Segregation }\end{array}$ & $\begin{array}{c}\text { Percent } \\
\text { Black }\end{array}$ & Dissimilarity & Isolation & & $\begin{array}{l}\text { Neighbor- } \\
\text { Based } \\
\text { Segregation }\end{array}$ & $\begin{array}{c}\text { Percent } \\
\text { Black }\end{array}$ & Dissimilarity & Isolation \\
\hline Neighbor-based segregation & 1 & & & & Neighbor-based segregation & 1 & & & \\
\hline Percent black & 0.68 & 1 & & & Percent black & 0.28 & 1 & & \\
\hline Dissimilarity & -0.44 & -0.5503 & 1 & & Dissimilarity & 0.14 & -0.53 & 1 & \\
\hline Isolation & 0.50 & 0.35 & 0.18 & 1 & Isolation & 0.69 & 0.06 & 0.50 & 1 \\
\hline
\end{tabular}

Sources: Authors' own calculations based on the IPUMS 100 percent sample of the 1880 federal census. 
of black households in each county these correlations turn positive. In general, the correlations in Table 1 show that our measure is weakly correlated with traditional measures of segregation. This is likely due to the fineness of our measure as opposed to the groupings required of traditional measures. For example, Echenique and Fryer propose a spectral index of segregation that is well correlated with the percent black (.90) and isolation (.93), but less well correlated with dissimilarity (.42). Our measure is substantially less well correlated with any of these measures $(.43, .55$, and .29 for percent black, isolation and dissimilarity, respectively) but does share the same general pattern of correlations. ${ }^{20}$

For a more detailed view of how the geographical distribution of segregation varies by measure, maps of the eastern and midwestern United States are given in Figure 2. The most striking feature is that the index of dissimilarity shows the North and, more generally, areas with a low percentage of black residents as more segregated on average while our neighbor-based measure identifies the South as more segregated (but not necessarily the areas of the South with dense populations). That is, the percent black and the index of dissimilarity do not reveal the same spatial pattern of segregation as our neighbor-measure does.

\section{City-Level Measures}

One striking feature of our segregation measure is that it yields stark differences in regional segregation patterns. When looking at dissimilarity, the results suggest that urban counties in the North were more segregated than those in the South. This is consistent with the city-level segregation estimates in Cutler, Glaeser, and Vigdor (1999). Our segregation measure, however, reveals the opposite pattern. This finding is not an artifact of using counties rather than cities; city-level estimates produce the same patterns. Means and standard deviations of our segregation measure and traditional measures at the city level weighted by number of black households are given in Table 2. Southern cities are the most segregated on the basis of next-door neighbors despite Northern cities appearing more segregated on the basis of traditional measures. The set of cities we use for this calculation is larger than the set used by Cutler, Glaeser, and Vigdor (1999) because they were limited to cities with populations greater than 25,000 . Since we use the complete 100

\footnotetext{
${ }^{20}$ Measures such as the sequence index of segregation, described in Grigoryeva and Ruef (2015) and Agresti (1980) are well correlated with dissimilarity in all regions except the South. Our measure is weakly correlated with dissimilarity and isolation over all regions.
} 


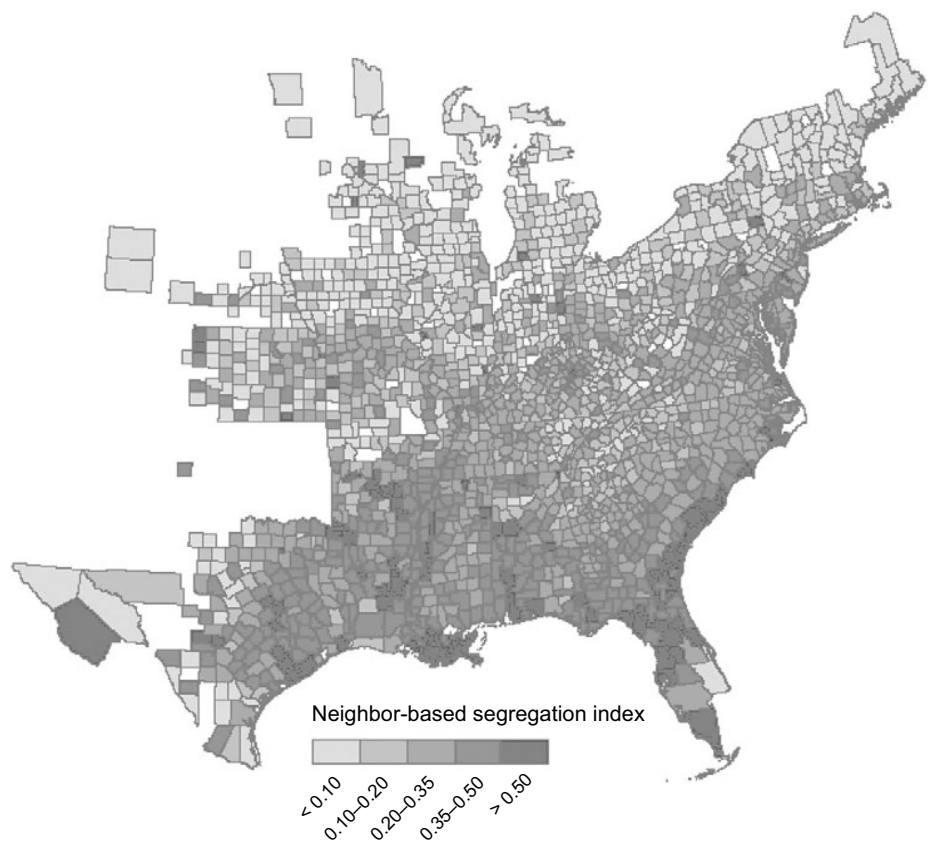

(a)

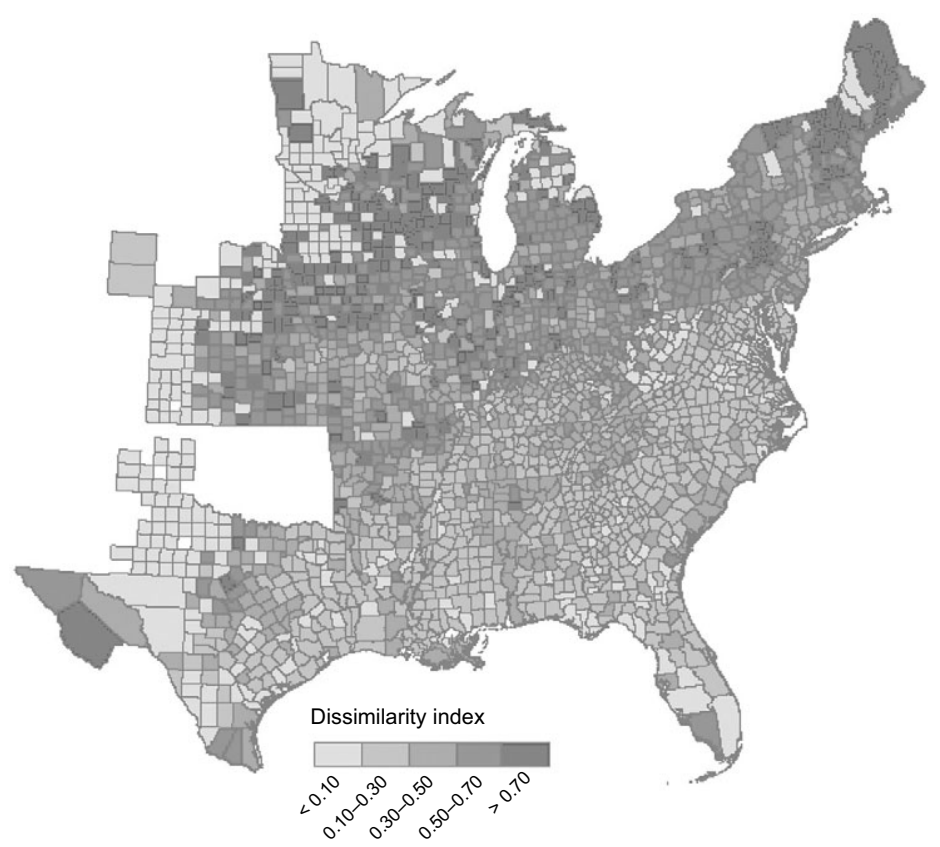

(b)

FIGURE 2

SEGREGATION MEASURES BY COUNTY, 1880: (A) OUR NEIGHBOR-BASED MEASURE AND (B) INDEX OF DISSIMILARITY 


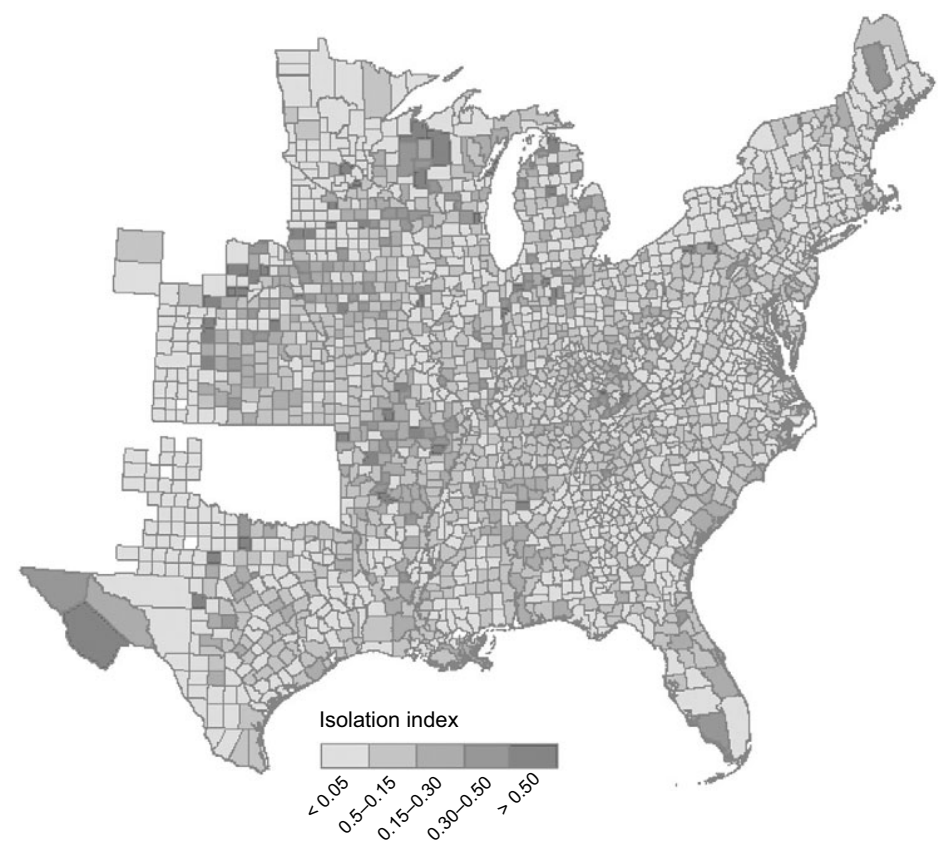

(c)

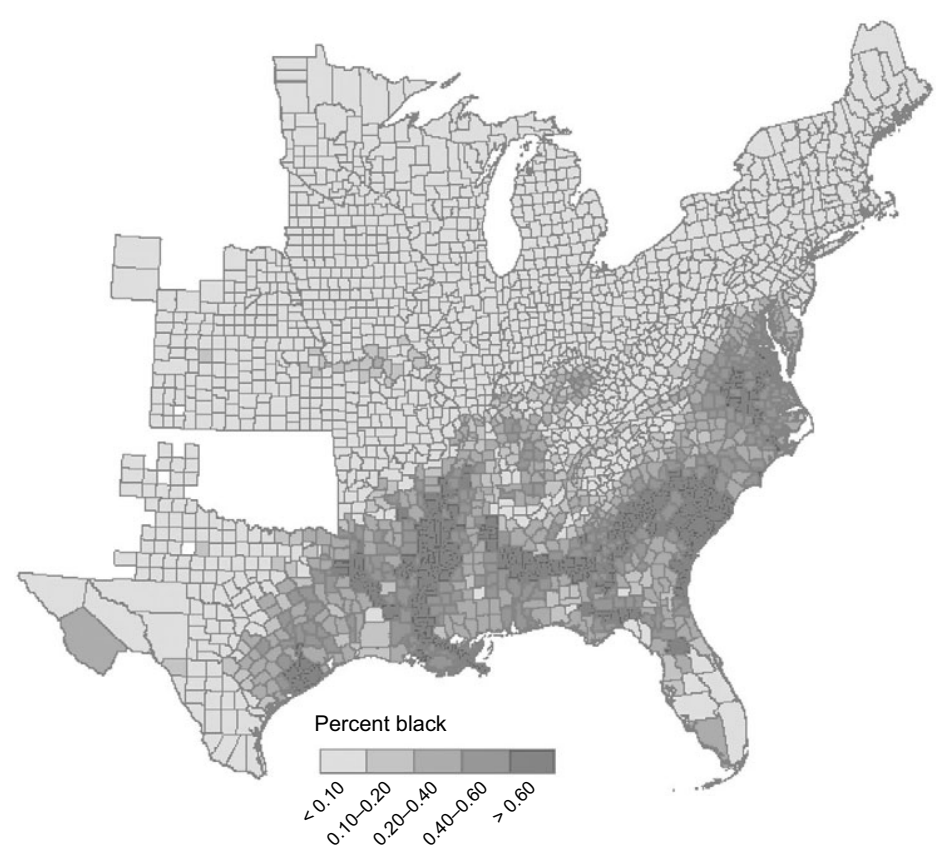

(d)

FIGURE 2 (CONTINUED)

SEGREGATION MEASURES BY COUNTY, 1880: (C) INDEX OF ISOLATION AND (D) PERCENT BLACK

Source: Authors' calculations based on IPUMS 100 percent sample of the 1880 federal census. 
TABLE 2

CITY-LEVEL SEGREGATION BY REGION WEIGHTED BY NUMBER OF BLACK HOUSEHOLDS, 1880

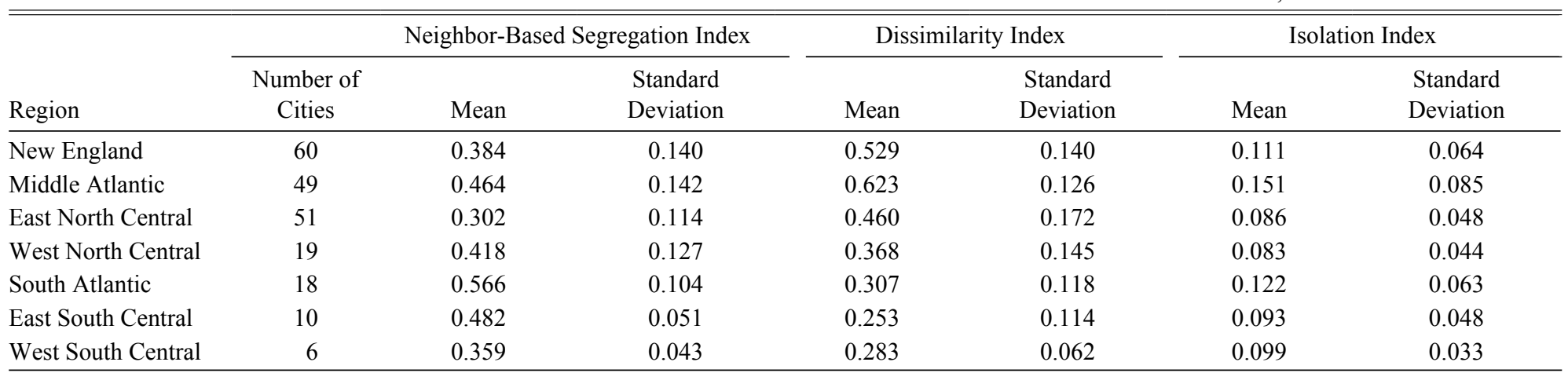

Sources: Authors' own calculations based on the IPUMS 100 percent sample of the 1880 federal census. Dissimilarity and isolation are calculated using enumeration district as the geographic subunit. 
percent sample of the census, we are able to look at all cities with populations more than 10,000 in the United States. Restricting our sample to the cities with populations greater than 25,000 produces the same patterns across regions as those in Table 2.

The city estimates reinforce our finding that traditional measures obscure a substantial amount of within-district segregation that is particularly pronounced in the South. The traditional measures of segregation, with their reliance on geographic boundaries and population shares, paint a portrait of regional differences in segregation that is not consistent with residential location patterns by race. Southern cities were the most segregated. While whites and blacks may have lived in the same wards and districts in Southern cities, they were much less likely to be neighbors compared to Northern cities. Such patterns are consistent with racial hierarchies mapping onto residential living patterns such as whites living on street-facing avenues and blacks living in dwellings that face an alley. This finding leads to a reinterpretation of the narrative of segregation-regional differences in segregation did not arise with black population inflows to Northern cities, they came from a preexisting segregated pattern in the South.

Given the maps for the traditional measures in Figure 2, one could make the argument that de jure racial restrictions in the South led to low levels of racial segregation. That is, if blacks were systematically restricted from access to public spaces, schools, and other public accommodations the residential pattern would not need to be segregated. This is reinforced by a noticeable discontinuous change in dissimilarity moving from South to North across the southern borders of Pennsylvania, Ohio, and Indiana. One would be tempted to conclude that institutional or cultural differences led to dramatic differences in residential segregation between the North and South. However, the map of our measure and the statistics in Figure 1 suggest that no such discontinuity exists; the South had substantial residential segregation in 1880 obscured by traditional measures but revealed by the neighbor-based measure.

\section{Segregation and Population Shares}

Until now, studies focused on racial differences in rural areas have had to characterize residential patterns by the percent black in a county. Studies of the strength of social networks and socioeconomic outcomes in the South (Munshi 2014), interracial economic competition and lynching (Beck and Tolnay 1990; Tolnay and Beck 1992), and even studies focused specifically on rural residential patterns of minority 
groups (Lichter and Johnson 2006) all rely on the black population share within a county. However, the distribution of the black population within a county is crucial to the theories of social interactions and economic competition underlying these studies. In panel (a) of Figure 3, we show that the percent of a county that is black is a relatively poor approximation of the level of segregation in the community. At each level of percent black in a county there is significant heterogeneity in the neighbor-based measure of segregation. Given the wide variation in segregation levels by percent black, counties with small and large black population shares could be equally segregated or more/less integrated than one another. This highlights the importance of having a household-level measure of segregation. It also suggests the importance of moving beyond a focus on black population shares when estimating tipping point models like those of Thomas Schelling (1969) and Card et al. (2008). The substantial heterogeneity in terms of how black populations are distributed suggests that communities with similar black population shares may have exhibited very different population dynamics if it is the racial composition of very local neighborhoods that matters to individuals when making migration decisions. This is salient both for the population dynamics underlying the historical migration of black individuals out of the South and the more modern movement of individuals from cities to suburbs and exurbs.

Moving beyond county-level estimates, our segregation measure can be calculated at the enumeration district level. This measure of sub-county segregation is not possible with traditional segregation measures - the enumeration district population shares are the input into traditional segregation measures, which cannot be further disaggregated. In panel (b) of Figure 3 we show the segregation measure and the percent black in each enumeration district in the United States. ${ }^{21}$ The dispersion in the relationship at the enumeration district level is even greater than at the county level, suggesting that a focus on percent black in rural and urban areas obscures a great deal of heterogeneity, and that this obscurity increases with the fineness of detail. The correlation of the segregation measure and percent black for enumeration districts is only 0.13 , even less than

\footnotetext{
${ }^{21}$ Note that a small number of enumeration districts have segregation levels that are less than zero or greater than one. Recall that zero is defined as random assignment of neighbors by race. In rare cases, there are more black households with white neighbors than we would predict based on random assignment, leading to a negative value for the index. As for the values greater than one, this is a product of missing households. In a perfectly segregated area, if the two black households at the end of the black neighborhood are either missing or have their next-door neighbors missing in the census manuscript, the segregation index can exceed one.
} 


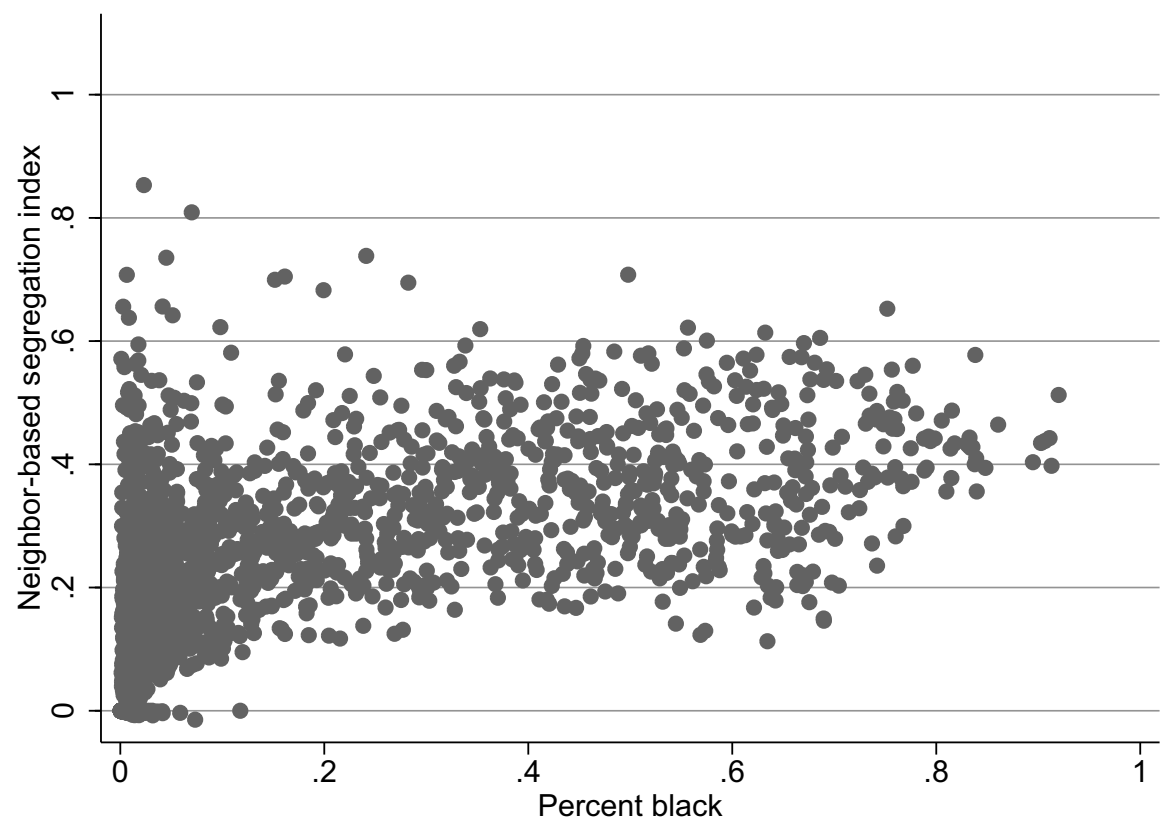

(a)

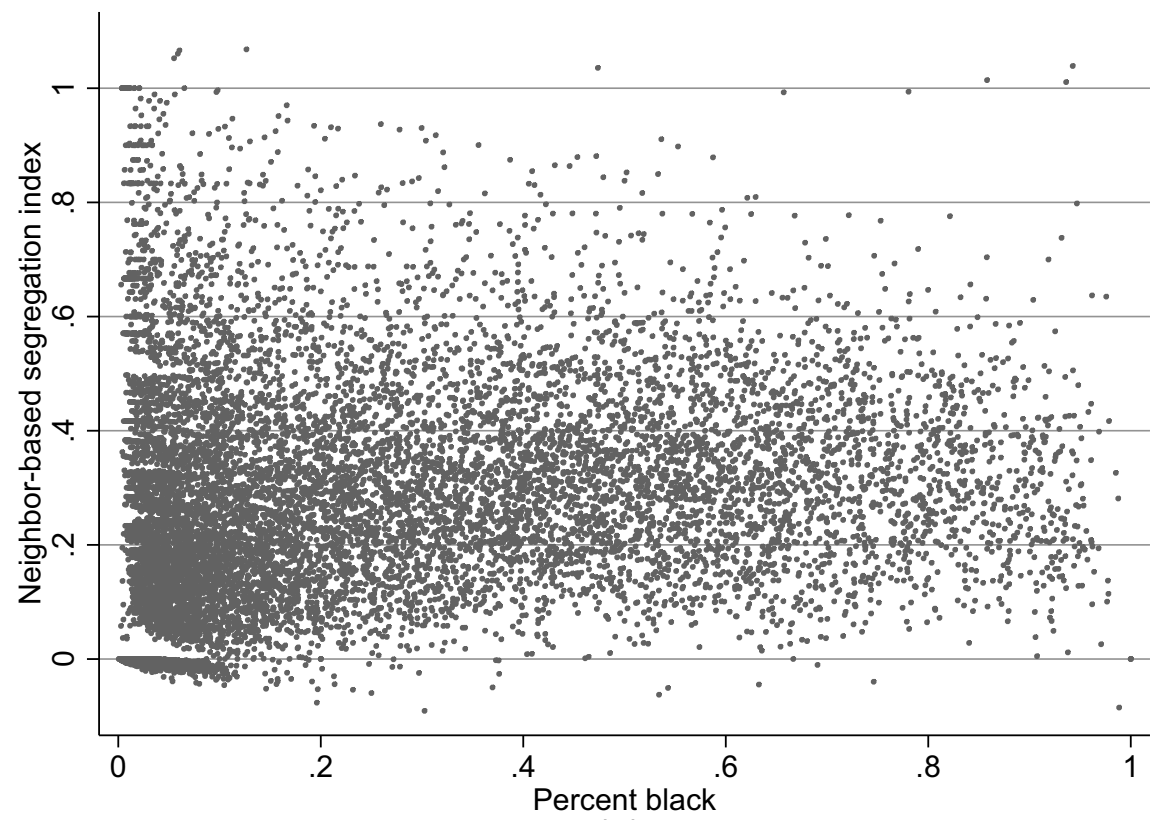

(b)

FIGURE 3

SEGREGATION AND THE PERCENTAGE BLACK BY: (A) ALL COUNTIES IN THE UNITED STATES; (B) ALL CENSUS ENUMERATION DISTRICTS IN THE UNITED STATES

Source: Authors' calculations based on the IPUMS 100 percent sample of the 1880 federal census. 
the county correlation of 0.43 . These low correlations suggest that the neighbor-based measure reveals substantial variation in segregation within counties across enumeration districts, variation that traditional segregation indices cannot capture.

\section{SEGREGATION OVER TIME}

The 1940 census offers a fascinating bookend to our study of residential segregation. The 1880 census comes after the Civil War and before the nation moved to Jim Crow. For example, at the time of the 1880 census, the Civil Rights Act of 1875, which guaranteed equal protection in public accommodation, was still in place although not necessarily enforced. The 1940 census, however, depicts residential patterns after the rise of Jim Crow, the Great Migration, and the influx of European immigrants. Importantly, the 1940 census comes largely before the rise of significant suburbanization seen in the post-war years. It is this period from the latenineteenth century to 1940 that Cutler, Glaeser, and Vigdor (1999) cite as the rise of the American ghetto. While urban segregation as measured by isolation and dissimilarity was generally rising, the segregation patterns across cities tended to persist over time, with the most segregated cities at the turn of the century also being the most segregated cities at the end of the century. ${ }^{22}$ The complete census returns for 1880 and 1940 allow us to see whether our neighbor-based segregation index shows a similar rise in urban segregation and whether a comparable change in segregation occurred in rural areas.

\section{Increasing Residential Segregation in Rural and Urban Counties}

We begin by focusing on county-level estimates by region. Table 3 shows the variation in our neighbor-based segregation index by census region in both 1880 and 1940 . All statistics are weighted by the number of black households in the county so they should be interpreted as representing the level of segregation experienced by the average black household. Counties are divided between rural and urban to distinguish between the segregation patterns described by Cutler, Glaeser, and Vigdor specific to cities and more general patterns affecting the rest of the population. As

\footnotetext{
${ }^{22}$ It is this variation in segregation across cities that Troesken (2002) exploits when looking at the health improvements resulting from the provision of water and sewerage service during the Jim Crow era. Cities that were more segregated as measured by the index of isolation saw smaller health improvements for black residents relative to white residents.
} 
TABLE 3

CHANGES IN THE COUNTY-LEVEL SEGREGATION INDEX FROM 1880 TO 1940 BY REGION, COUNTIES WEIGHTED BY NUMBER OF BLACK HOUSEHOLDS

\begin{tabular}{|c|c|c|c|c|c|c|}
\hline \multirow[b]{2}{*}{ Region } & \multicolumn{3}{|c|}{ Rural Counties } & \multicolumn{3}{|c|}{ Urban Counties } \\
\hline & $\begin{array}{c}1880 \\
(1)\end{array}$ & $\begin{array}{c}1940 \\
(2)\end{array}$ & $\begin{array}{c}\text { 1940-1880 } \\
\text { (2)-(1) } \\
\text { (3) }\end{array}$ & $\begin{array}{c}1880 \\
(4)\end{array}$ & $\begin{array}{c}1940 \\
(5)\end{array}$ & $\begin{array}{c}1940-1880, \\
(5)-(4) \\
(6)\end{array}$ \\
\hline New England & $\begin{array}{c}0.12 \\
(0.10)\end{array}$ & $\begin{array}{c}0.33 \\
(0.17)\end{array}$ & 0.21 & $\begin{array}{c}0.33 \\
(0.13)\end{array}$ & $\begin{array}{c}0.56 \\
(0.18)\end{array}$ & 0.23 \\
\hline Middle Atlantic & $\begin{array}{c}0.23 \\
(0.13)\end{array}$ & $\begin{array}{c}0.39 \\
(0.11)\end{array}$ & 0.16 & $\begin{array}{c}0.40 \\
(0.17)\end{array}$ & $\begin{array}{c}0.75 \\
(0.15)\end{array}$ & 0.35 \\
\hline East North Central & $\begin{array}{c}0.23 \\
(0.13)\end{array}$ & $\begin{array}{c}0.43 \\
(0.24)\end{array}$ & 0.20 & $\begin{array}{c}0.29 \\
(0.12)\end{array}$ & $\begin{array}{c}0.80 \\
(0.17)\end{array}$ & 0.51 \\
\hline West North Central & $\begin{array}{c}0.25 \\
(0.10)\end{array}$ & $\begin{array}{c}0.43 \\
(0.13)\end{array}$ & 0.18 & $\begin{array}{c}0.38 \\
(0.14)\end{array}$ & $\begin{array}{c}0.74 \\
(0.20)\end{array}$ & 0.36 \\
\hline South Atlantic & $\begin{array}{c}0.30 \\
(0.10)\end{array}$ & $\begin{array}{c}0.54 \\
(0.16)\end{array}$ & 0.24 & $\begin{array}{c}0.50 \\
(0.11)\end{array}$ & $\begin{array}{c}0.74 \\
(0.13)\end{array}$ & 0.24 \\
\hline East South Central & $\begin{array}{c}0.37 \\
(0.09)\end{array}$ & $\begin{array}{c}0.57 \\
(0.09)\end{array}$ & 0.20 & $\begin{array}{c}0.44 \\
(0.05)\end{array}$ & $\begin{array}{c}0.78 \\
(0.10)\end{array}$ & 0.34 \\
\hline West South Central & $\begin{array}{c}0.44 \\
(0.09)\end{array}$ & $\begin{array}{c}0.61 \\
(0.09)\end{array}$ & 0.17 & $\begin{array}{c}0.39 \\
(0.08)\end{array}$ & $\begin{array}{c}0.71 \\
(0.12)\end{array}$ & 0.32 \\
\hline Mountain & $\begin{array}{c}0.28 \\
(0.29)\end{array}$ & $\begin{array}{c}0.40 \\
(0.32)\end{array}$ & 0.12 & $\begin{array}{c}0.31 \\
(0.14)\end{array}$ & $\begin{array}{c}0.40 \\
(0.18)\end{array}$ & 0.09 \\
\hline Pacific & $\begin{array}{c}0.07 \\
(0.13) \\
\end{array}$ & $\begin{array}{c}0.40 \\
(0.32) \\
\end{array}$ & 0.33 & $\begin{array}{c}0.06 \\
(0.05) \\
\end{array}$ & $\begin{array}{c}0.58 \\
(0.19) \\
\end{array}$ & 0.52 \\
\hline Entire country & $\begin{array}{c}0.35 \\
(0.11)\end{array}$ & $\begin{array}{c}0.57 \\
(0.13)\end{array}$ & 0.22 & $\begin{array}{c}0.43 \\
(0.13)\end{array}$ & $\begin{array}{c}0.75 \\
(0.15)\end{array}$ & 0.32 \\
\hline
\end{tabular}

Notes: Means are reported with standard deviations given in parentheses. All means and standard deviations are weighted by the number of black households in the county. Urban counties are defined as those having greater than 25 percent of inhabitants living in an urban area. The urbanrural distinction is based on the year the statistic corresponds to, so some of the counties in the 1880 rural calculations appear in the 1940 urban calculations.

Sources: Authors' own calculations based on the 100 percent samples of the 1880 and 1940 federal censuses.

noted earlier, we designate a county as urban if more than one-quarter of the households from that county live in an urban area and rural if less than one-quarter of the households live in an urban area. For 1880, this leads to 88 percent of counties being classified as rural. For 1940, 60 percent of counties are classified as rural.

The table shows several stark trends. First, segregation varied substantially across regions. Southern regions, in particular the East South Central and West South Central regions, were substantially more segregated than the North or the Midwest. This is true in both 1880 and 1940 and for both rural and urban counties. The higher level of segregation in Southern cities established in the previous section persisted over time despite the dramatic increases in segregation in other areas of the country. 
The truly striking feature of Table 3 is the difference between the 1880 and 1940 segregation levels, given in columns (3) and (6) for rural and urban counties, respectively. In all regions, there is a substantial increase in segregation in urban areas. The increases are particularly large in regions that were receiving large inflows of black residents during the Great Migration; the largest changes in segregation are for the urban areas in the East North Central and West North Central regions. ${ }^{23}$ However, the table suggests that the story of rising segregation levels is not strictly an urban story. While the first decades of the twentieth century may have seen the rise of the American ghetto, they also witnessed a substantial rise in rural segregation levels as well. All of the regions show substantial increases in segregation comparable in size to one to two standard deviations of the county-level segregation index distribution. Between 1880 and 1940 the United States became more segregated overall — urban and rural, North and South. ${ }^{24}$

This rise in segregation across all regions is not simply a story of black households becoming concentrated in selected counties. Table A5 in the Online Appendix shows the variation in percent black by region and over time. There were modest increases in the percentage of households with black household heads by county in the Northeast and Midwest but there were actually declines in the percentage of black households for the South. These patterns hold for both rural and urban counties and are consistent with mass migration. Despite the North and the South experiencing very different demographic change in terms of the distribution of black households across counties, all regions experienced an increase in segregation within counties whether those counties were urban or rural.

Regressing 1940 segregation levels on 1880 segregation levels, shown in Table 4, reveals the strong persistence of differences in segregation across locations and a general, dramatic increase in segregation across all locations. The baseline regression given in the first column yields a large slope coefficient of 0.815 , suggesting strong persistence in differences in segregation across locations over time. ${ }^{25}$ The large intercept of 0.237 ,

\footnotetext{
${ }^{23}$ It is important to note that this rise in segregation precedes the larger outflows of whites from central cities in the postwar era. Boustan (2010) estimates that each black migrant after WWII resulted in more than one white exodus from the central city.

${ }^{24}$ One concern is that changes in the segregation index over time may simply be the product of changes in county boundaries, not changes in the actual residential patterns of black and white individuals. In Table A10 of the Online Appendix, we provide estimates of the change in segregation over time excluding counties that merged in between 1880 and 1940 and excluding counties that had any sort of boundary change between 1880 and 1940. The same patterns hold.

${ }^{25}$ This regression is unweighted by black population shares. Although there is strong persistence, tests of a unit root in the segregation measure were rejected at all conventional levels. A basic Dickey Fuller test of the change in the segregation measure on the 1880 segregation measure yields a slope coefficient of -0.199 ( 0.030 s.e.).
} 
TABLE 4

THE PERSISTENCE OF SEGREGATION, 1880-1940, SEGREGATION IN 1940 AS DEPENDENT VARIABLE

\begin{tabular}{|c|c|c|c|c|c|}
\hline Segregation in 1880 & $\begin{array}{c}0.815^{* * *} \\
(0.030)\end{array}$ & $\begin{array}{c}0.566 * * * \\
(0.033)\end{array}$ & $\begin{array}{c}0.582 * * * \\
(0.034)\end{array}$ & $\begin{array}{c}0.549 * * * \\
(0.034)\end{array}$ & $\begin{array}{c}0.535 * * * \\
(0.033)\end{array}$ \\
\hline Change in percent black, $1880-1940$ & & & $\begin{array}{c}0.141 * * \\
(0.064)\end{array}$ & $\begin{array}{c}0.161 * * \\
(0.063)\end{array}$ & $\begin{array}{c}0.200 * * * \\
(0.062)\end{array}$ \\
\hline Urban county in 1880 & & & & $\begin{array}{c}0.117 * * * \\
(0.014)\end{array}$ & $\begin{array}{c}0.030^{*} \\
(0.18)\end{array}$ \\
\hline Log of urban population & & & & & $\begin{array}{c}0.015 * * * \\
(0.002)\end{array}$ \\
\hline Constant & $\begin{array}{c}0.237 * * * \\
(0.009)\end{array}$ & $\begin{array}{c}0.219 * * * \\
(0.010)\end{array}$ & $\begin{array}{c}0.217 * * * \\
(0.010)\end{array}$ & $\begin{array}{c}0.195 * * * \\
(0.010)\end{array}$ & $\begin{array}{c}0.160 * * * \\
(0.011)\end{array}$ \\
\hline Census region fixed effects & & $\mathrm{X}$ & $\mathrm{X}$ & $\mathrm{X}$ & $\mathrm{X}$ \\
\hline Observations & 1,868 & 1,868 & 1,868 & 1,868 & 1,868 \\
\hline R-squared & 0.278 & 0.354 & 0.355 & 0.380 & 0.399 \\
\hline
\end{tabular}

$*$ Significant at the 10 percent level.

$* *=$ Significant at the 5 percent level.

$* * *=$ Significant at the 1 percent level.

Notes: Ordinary least squares (OLS) estimates with standard errors given in parentheses. The unit of observation is a county. Counties are defined as urban if greater than 25 percent of the county population lives in an urban area.

Sources: Authors' own calculations based on the 100 percent sample of the 1880 and 1940 federal censuses.

coupled with the large slope coefficient, suggests that county-level segregation rose substantially on average: the county level mean essentially doubled from 1880 to 1940 , rising from 0.22 to $0.42 .{ }^{26}$ Regional controls do not alter the substantive implications. Even when adding changes in the percent black, regional controls, and urban population, the point estimates for 1880 segregation remain large.

\section{Increasing Segregation in American Cities}

Looking at segregation at the city level reinforces the findings that rising segregation is not strictly a northern phenomenon and that segregation in Southern cities was more pronounced than in Northern cities. Table 5 shows the mean level of segregation in 1940 for cities by region. As with the results in Table 2, Northern cities were less segregated than Southern cities. The level of segregation in cities in all regions, however, is much higher in 1940 than in 1880.

\footnotetext{
${ }^{26}$ The traditional segregation measures do not show the same persistence. Dissimilarity has a coefficient estimate of 0.430 ( 0.022 s.e. $)$ and isolation a coefficient estimate of $-0.003(0.019$ s.e.) in regressions of historical persistence. See the Online Appendix Table A6 for the full specification.
} 
TABLE 5

CITY-LEVEL SEGREGATION BY REGION WEIGHTED BY NUMBER OF BLACK HOUSEHOLDS, 1940

\begin{tabular}{|c|c|c|c|c|c|c|c|}
\hline \multirow[b]{2}{*}{ Region } & \multicolumn{3}{|c|}{ Neighbor-Based Segregation Index } & \multicolumn{2}{|c|}{ Dissimilarity Index } & \multicolumn{2}{|c|}{ Isolation Index } \\
\hline & $\begin{array}{c}\text { Number of } \\
\text { Cities }\end{array}$ & Mean & $\begin{array}{l}\text { Standard } \\
\text { Deviation }\end{array}$ & Mean & $\begin{array}{l}\text { Standard } \\
\text { Deviation }\end{array}$ & Mean & $\begin{array}{c}\text { Standard } \\
\text { Deviation }\end{array}$ \\
\hline New England & 54 & 0.607 & 0.187 & 0.789 & 0.095 & 0.349 & 0.198 \\
\hline Middle Atlantic & 44 & 0.794 & 0.087 & 0.852 & 0.064 & 0.616 & 0.142 \\
\hline East North Central & 47 & 0.845 & 0.128 & 0.893 & 0.084 & 0.714 & 0.199 \\
\hline West North Central & 19 & 0.809 & 0.150 & 0.847 & 0.101 & 0.641 & 0.211 \\
\hline South Atlantic & 16 & 0.904 & 0.042 & 0.772 & 0.111 & 0.641 & 0.136 \\
\hline East South Central & 10 & 0.872 & 0.033 & 0.720 & 0.102 & 0.574 & 0.121 \\
\hline West South Central & 6 & 0.801 & 0.062 & 0.698 & 0.062 & 0.542 & 0.104 \\
\hline
\end{tabular}

Sources: Authors' own calculations based on the 100 percent sample of the 1940 federal census. Dissimilarity and isolation are calculated using enumeration district as the geographic subunit. 


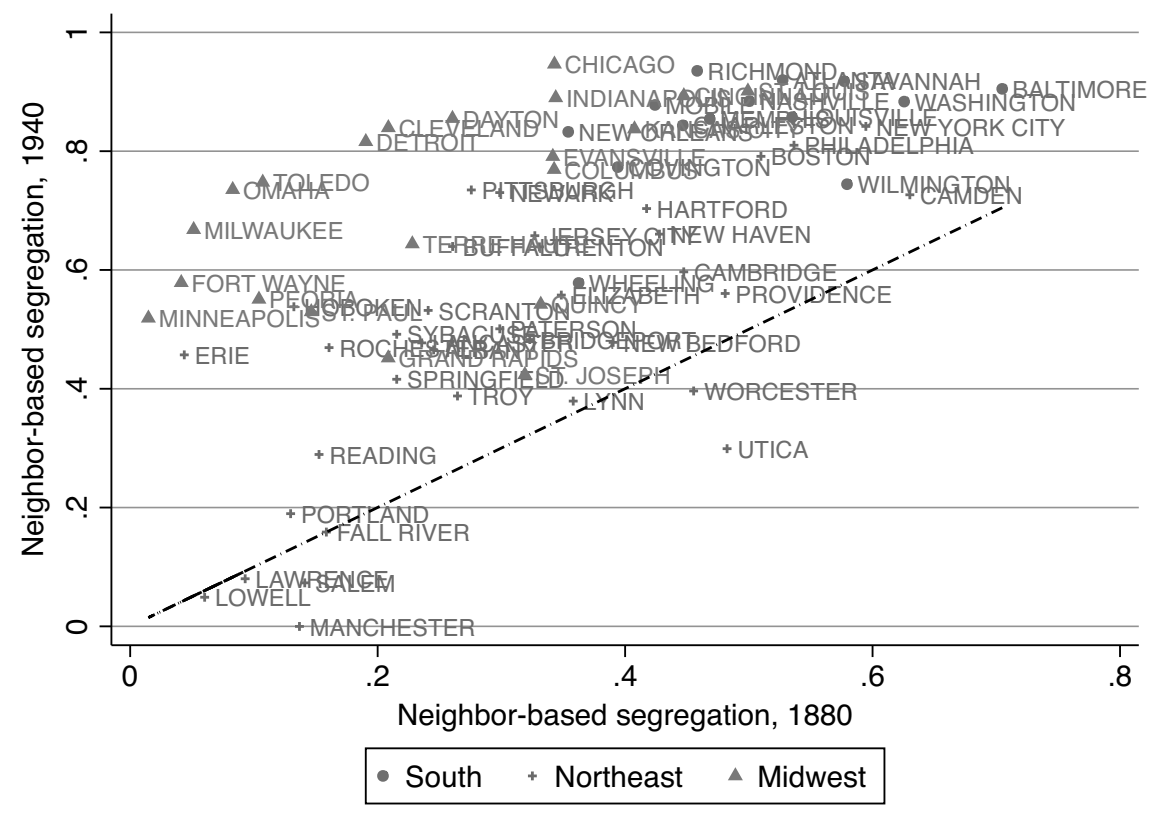

FIGURE 4

CITY-LEVEL SEGREGATION IN 1880 AND 1940

Notes: All cities with populations with more than 10,000 people in 1880 are included in the sample. A 45-degree line is plotted as a dashed line.

Source: Authors' calculations based on the 100 percent samples of the 1880 and 1940 federal censuses.

Figure 4 plots the neighbor-based segregation index for 1940 against the index for 1880 for cities in the Northeast, South, and Midwest. Consistent with the county-level results, nearly every city across all regions lies above the 45-degree line, with higher levels of segregation in 1940 than in 1880. However, the striking feature of the graph is that the Southern cities exhibited the highest levels of segregation in both 1880 and 1940 while Midwestern cities that experienced large inflows of black migrants experienced some of the highest increases in segregation. While there is a wide range of segregation levels for Northeastern cities, the rise in neighbor-based segregation for these cities is less pronounced than the rise for the Midwest and the South. The regional variation in Figure 4 coupled with the changes in segregation over time for rural counties in Table 3 suggest that the rise of the American ghetto described by Cutler, Glaeser, and Vigdor is one piece of a much larger and more complex story of increasing residential segregation in the United States over the first half of the twentieth century. 
Racial Sorting and the Likelihood of Opposite-Race Neighbors

Over Time

The neighbor-based segregation measure highlights the extent to which racial sorting reduced opposite-race interactions over time. The large increases in our measure suggest that even in locations where rising black population shares would suggest increasing likelihood of white households having black neighbors, growth in the number of oppositerace neighbors was substantially muted by increased sorting. The role of sorting at the household level over time has played a large role in the narrative of segregation but has not been empirically analyzed in detail. A simple way to demonstrate the extent to which the rise in racial sorting reduced opposite-race interactions is to look at the percentage of black or white households with a neighbor of the opposite race, a number that depends both on the racial composition of the local area and the household-level sorting captured by our measure.

While the presence of an opposite-race neighbor does not guarantee opposite-race social interactions, it is reasonable to assume that a decline in the number of opposite-race neighbors would be correlated with a decline in opposite-race interactions. Overall, in the unweighted median county in 1880 a black household had roughly a 50 percent chance of having a white neighbor. By 1940, however, this likelihood declined by more than 15 percentage points, a decrease of more than 25 percent in the likelihood of an opposite-race neighbor. Using only areas where blacks were greater than 1 percent of the population in 1880 results in more than a 25 percentage point decline in the likelihood, a decrease of more than 35 percent. $^{27}$

These declines suggest substantially reduced exposure of individuals to opposite-race neighbors over time. Consider the example of Chicago, a city that went from moderate levels of segregation in 1880 to the highest level of segregation in 1940. While the black population share rose from 1.2 percent to 7.7 percent of the city population, the percentage of white households with a black neighbor declined from 1 percent to 0.4 percent. The percentage of black households with a white neighbor declined from 66 percent to only 5 percent. Compounding these declines is a reduction in the number of individuals living with their employer, an additional

\footnotetext{
${ }^{27}$ The result also holds when using larger cutoffs for the percentage of the black population in 1880. In general, the increase in racial isolation is not driven by black migration to areas where the black population was small in 1880 .
} 
and important source of interracial interaction not captured by the nextdoor neighbor measure. From 1880 to 1940, the ratio of black individuals living with their employers relative to black household heads fell from 0.27 to $0.04 .^{28}$

This significant change in the degree of opposite-race neighbors holds across regions that saw relative declines and increases in the black population, across urban and rural areas, and across large and small populations. ${ }^{29}$ These findings add a new dimension to the changing residential patterns of the late nineteenth and early twentieth centuries. At a minimum, the results suggest that increasing racial isolation was not driven solely by urbanization or the Great Migration: racial sorting at the household level was a truly national trend in the twentieth century.

\section{EXPLORING THE NATIONAL RISE IN SEGREGATION}

While the national level change in segregation is noteworthy, it is important to establish that the increase in segregation is not simply a mechanical function of population growth or driven by outliers where either the population or racial composition changed dramatically. For example, the measure could increase (decrease) as more counties gained (lost) black residents with the Great Migration. We address these concerns in Figure 5 and Figure 6. In Figure 5 we show that the change in segregation was quite general. The level changes in neighbor-based segregation are not concentrated in a small number of counties nor one region of the country. Consistent with the results of Table 4, the vast majority of counties in every region saw substantial increases in segregation.

In Figure 6 we show the distribution of the change in the neighborbased segregation measure against other measures of population change for Northern and Southern counties to further test the traditional narrative of black migration from the rural South to the urban South and North leading to increases in segregation. In panels (a) and (b) of Figure 6 we show that the change in the segregation measure is not driven mechanically by increases in the number of black households. When we plot the change in the segregation measure by the change in the log of the number of black households the relationship shows a muted upward

\footnotetext{
${ }^{28}$ Note that this decline is not strictly the result of racial segregation; the ratio of white individuals living with their employers witnessed a similar decline from 0.14 to 0.03 . A simple regression of regional changes in neighbor-based segregation on changes in the ratio of black individuals living with their employers relative to black household heads produces a positive, statistically insignificant coefficient. These statistics are based on the authors' own calculations using the 1 percent IPUMS samples of the 1880 and 1940 federal censuses. Summary statistics are provided in Table A8 and Table A9 of the Online Appendix.

${ }^{29}$ These results are summarized in Table A11 of the Online Appendix.
} 


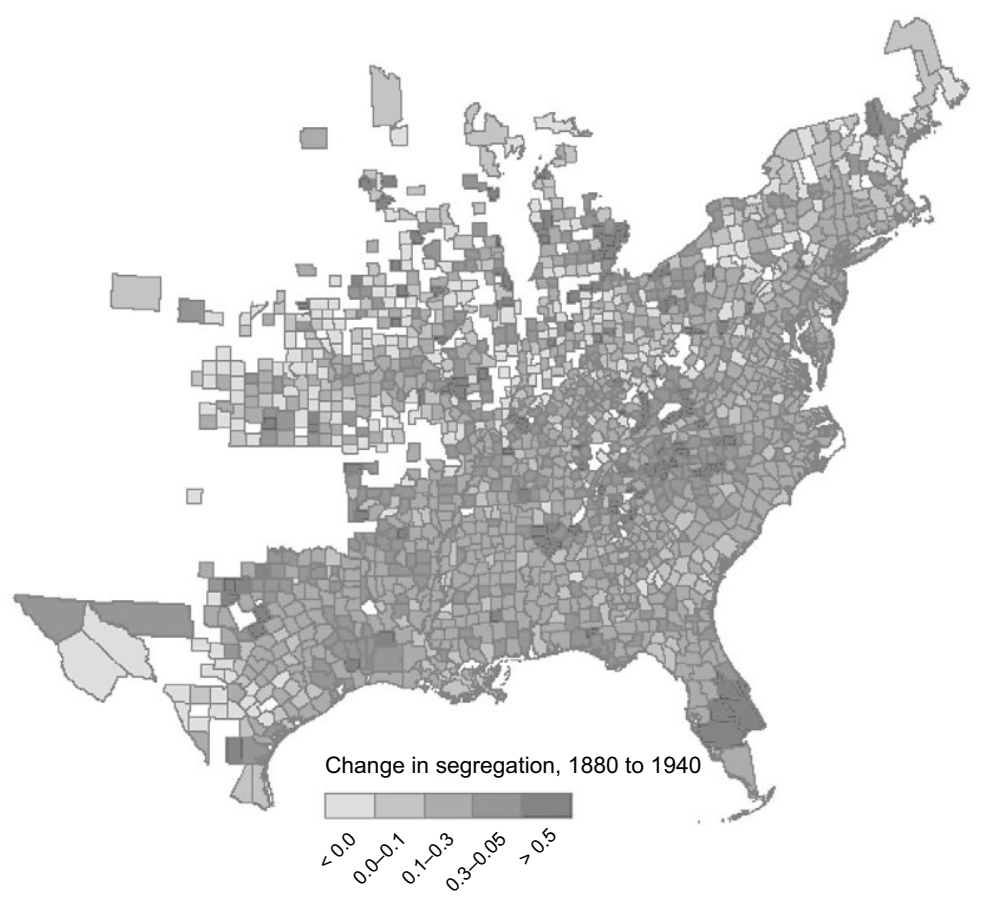

FIGURE 5

CHANGE IN THE NEIGHBOR-BASED MEASURE OF SEGREGATION, 1880-1940

Source: Authors' calculations based on the 100 percent samples of the 1880 and 1940 federal censuses.

trend but there are still substantial increases in segregation in counties that experienced significant declines in the black population as well. This is consistent with segregation being driven by sorting as opposed to population flows. In panels (c) and (d) of Figure 6 we plot the change in the segregation measure against the log of the number of households in 1880 and find that the change in segregation was observed for both large and small counties. Panels (e) and (f) plot the change against the percent black in 1880, revealing that counties with small and large proportions of black households experienced similar changes in segregation. Finally, panels $(\mathrm{g})$ and $(\mathrm{h})$ plotting the change in segregation against the change in the percent black from 1880 to 1940 demonstrate that the result is not driven by counties where African American population share grew or declined substantially. Overall, the traditional story that black migration drove increasing racial segregation, either in the North or in the South, appears incomplete. While panels (a) and (b) show a positive relationship between the change in segregation and growth of the black population, substantial increases in segregation also occurred in counties losing black residents and areas with declining population shares. 
(a) Northern counties

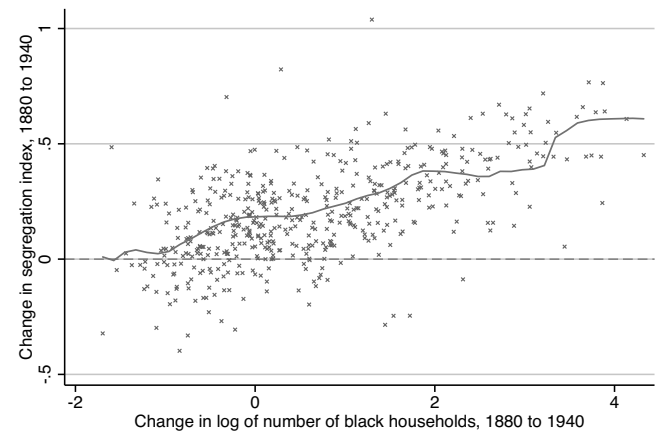

(b) Southern counties

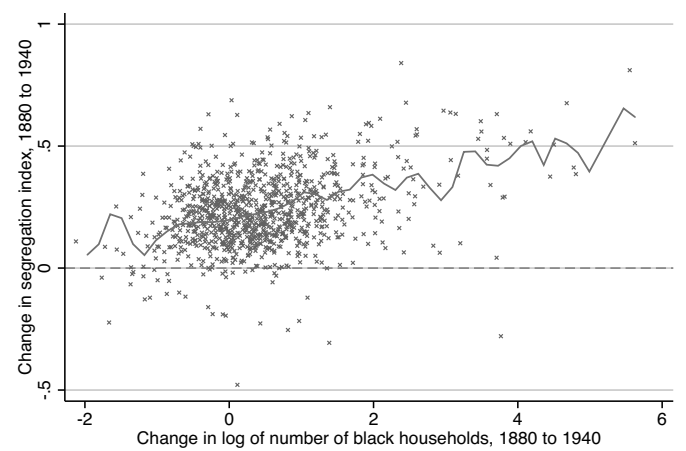

(c) Northern counties

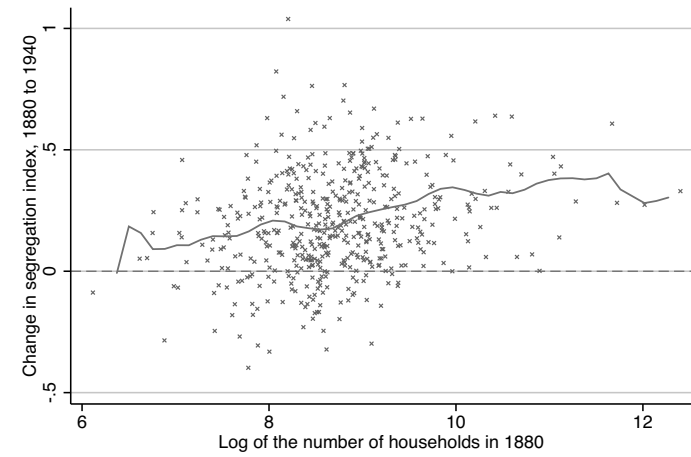

(d) Southern counties

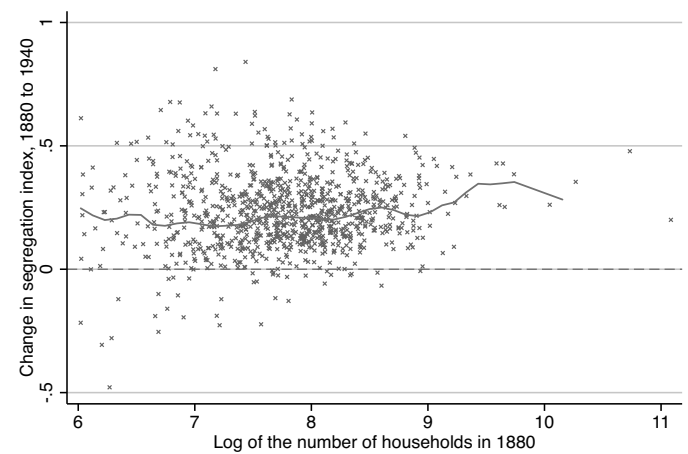

FIGURE 6

CHANGES IN SEGREGATION BY COUNTY, 1880-1940, BY: (A, B) THE CHANGE IN THE LOG OF THE NUMBER OF BLACK HOUSEHOLDS, 1880-1940 AND (C, D) THE LOG NUMBER OF TOTAL HOUSEHOLDS IN 1880 
(e) Northern counties

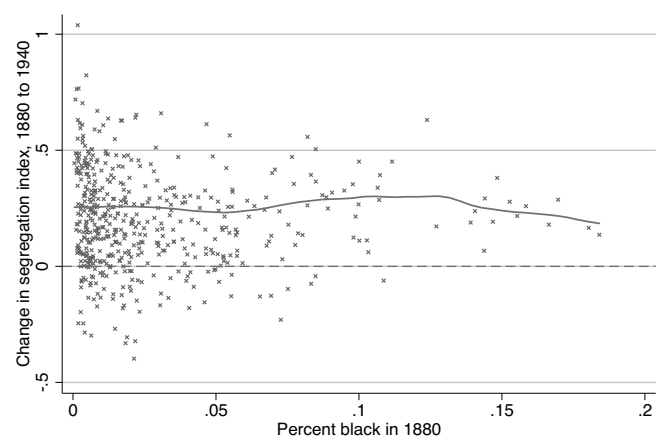

(f) Southern counties

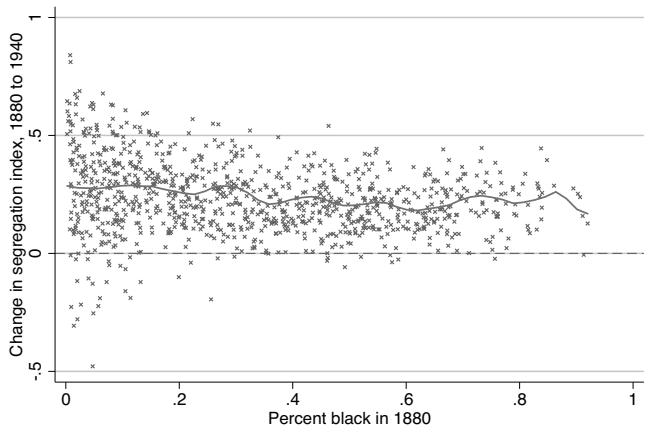

(g) Northern counties

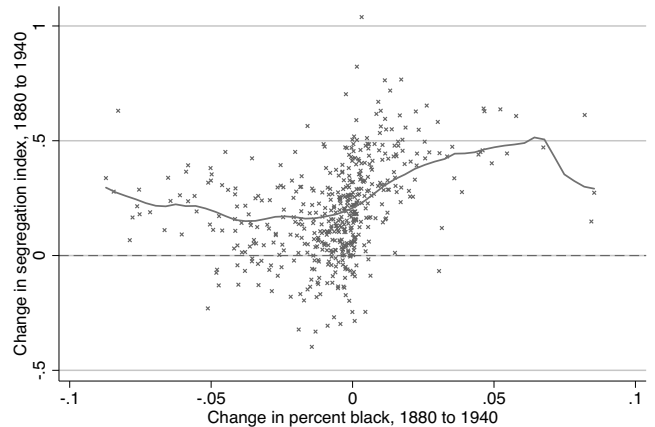

(h) Southern counties

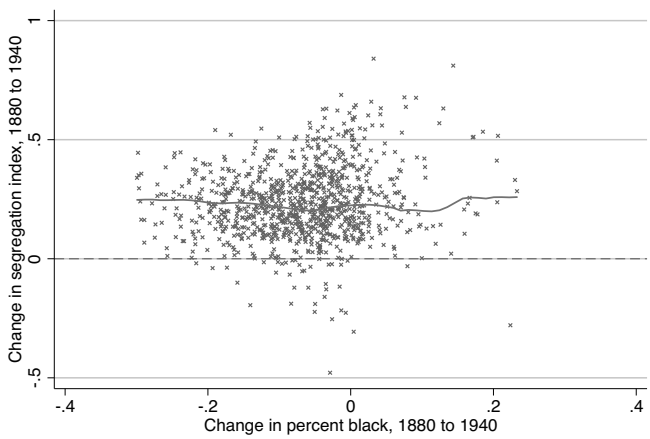

FIGURE 6 (CONTINUED)

CHANGES IN SEGREGATION BY COUNTY, 1880-1940, BY: (E, F) THE PERCENT BLACK IN 1880 AND (G, H) CHANGE IN THE PERCENT BLACK, 1880-1940

Note: The solid lines are unweighted local polynomial smooth fits.

Source: Authors' calculations based on the 100 percent samples of the 1880 and 1940 federal censuses. 
Further clouding the traditional narrative are the changes in rural segregation relative to urban segregation. Using dissimilarity, rural segregation increased 48 percent while urban segregation increased by 86 percent. Using isolation, rural segregation increased 112 percent while urban segregation increased by more than 300 percent. However, when measuring segregation at the household level rather than ward level, we find that segregation was not primarily an urban phenomenon. Our neighbor-based measure of segregation shows that both rural and urban segregation increased by roughly the same amount (62 percent for rural areas and 68 percent for urban areas). While urban areas became more segregated, rural residents sorted by race as well in a way that is not easily captured in existing segregation measures or explained by existing theories of white flight.

This rise in rural segregation presents an entirely new set of issues for explaining the roots of segregation and its consequences given that traditional narratives have focused on urban issues. While a full exploration of these issues is beyond the scope of this article, Table 6 presents a series of linear regressions examining which rural county characteristics in the South are correlated with levels of and changes in neighborbased segregation. Consistent with the history literature suggesting that free blacks tended to live in segregated communities in the antebellum South (Spain 1979; Fischer 1969; Sumpter 2008), we find the percentage of black population that is free in 1860 to be positively related to levels of segregation in 1880 but not predictive of changes in segregation from 1880 to 1940 . One might assume that areas with large slave plantations prior to the Civil War would have different segregation patterns after the Civil War. However, we find no significant relationship between the number of large slave plantations in 1860 and segregation in 1880 and only a very weak positive relationship between the presence of large slave plantations and rising segregation over time. Counties with larger farms tended to be less segregated in 1880 but followed the same trend over time as other counties. Given existing studies linking changes in the cotton economy to black migratory patterns (Higgs 1976; Holley 2000), cotton production may also factor into segregation patterns. However, we find that counties with higher levels of cotton production are no more or less segregated than other counties either in 1880 or over time. Finally, given the segregation in industry documented by Gavin Wright (1986), we explore whether the share of manufacturing in a county is related to segregation, a possibility if occupational segregation in manufacturing was related to residential segregation through households living near their place of employment. Counties with more manufacturing in 1860 did tend to be more segregated in 1880 and to experience larger increases 
TABLE 6

RURAL CHARACTERISTICS AND SEGREGATION IN THE SOUTH

\begin{tabular}{|c|c|c|c|c|c|c|}
\hline & \multicolumn{3}{|c|}{ Segregation in 1880} & \multicolumn{3}{|c|}{ Change in Segregation, 1880 to 1940} \\
\hline & (1) & (2) & (3) & (4) & (5) & (6) \\
\hline Percent free black & $\begin{array}{c}0.0344 \\
(0.0299)\end{array}$ & $\begin{array}{c}0.0866 * * \\
(0.0337)\end{array}$ & $\begin{array}{l}0.00975 \\
(0.0391)\end{array}$ & $\begin{array}{l}-0.0253 \\
(0.0441)\end{array}$ & $\begin{array}{l}-0.0429 \\
(0.0493)\end{array}$ & $\begin{array}{c}0.0104 \\
(0.0577)\end{array}$ \\
\hline $\begin{array}{l}\text { Large slave } \\
\quad \text { Plantations in } 1860\end{array}$ & $\begin{array}{l}-8.47 \mathrm{e}-05 \\
(5.64 \mathrm{e}-05)\end{array}$ & $\begin{array}{l}-3.65 e-05 \\
(6.01 e-05)\end{array}$ & $\begin{array}{l}-5.35 \mathrm{e}-05 \\
(6.28 \mathrm{e}-05)\end{array}$ & $\begin{array}{c}0.000161^{* *} \\
(8.12 \mathrm{e}-05)\end{array}$ & $\begin{array}{c}0.000144 \\
(8.73 \mathrm{e}-05)\end{array}$ & $\begin{array}{c}0.000136 \\
(9.17 \mathrm{e}-05)\end{array}$ \\
\hline Large farms, 1860 & $\begin{array}{l}-0.000121 \text { *** } \\
\quad(2.83 \mathrm{e}-05)\end{array}$ & $\begin{array}{c}-0.000178 * * * \\
(3.21 \mathrm{e}-05)\end{array}$ & $\begin{array}{l}-0.000133^{* * *} \\
\quad(3.42 \mathrm{e}-05)\end{array}$ & $\begin{array}{l}-7.04 \mathrm{e}-06 \\
(4.09 \mathrm{e}-05)\end{array}$ & $\begin{array}{l}4.43 \mathrm{e}-05 \\
(4.68 \mathrm{e}-05)\end{array}$ & $\begin{array}{c}4.11 \mathrm{e}-05 \\
(5.02 \mathrm{e}-05)\end{array}$ \\
\hline Percent black 1880 & $\begin{array}{l}0.372 * * * \\
(0.0227)\end{array}$ & $\begin{array}{c}0.380 * * * \\
(0.0239)\end{array}$ & $\begin{array}{c}0.349 * * * \\
(0.0258)\end{array}$ & $\begin{array}{c}-0.192 * * * \\
(0.0331)\end{array}$ & $\begin{array}{c}-0.210 * * * \\
(0.0350)\end{array}$ & $\begin{array}{c}-0.189 * * * \\
(0.0381)\end{array}$ \\
\hline $\begin{array}{l}\text { Cotton production } \\
\text { in } 1860\end{array}$ & & $\begin{array}{l}-2.95 \mathrm{e}-08 \\
(1.96 \mathrm{e}-08)\end{array}$ & $\begin{array}{l}-2.71 \mathrm{e}-08 \\
(1.87 \mathrm{e}-08)\end{array}$ & & $\begin{array}{l}4.89 \mathrm{e}-09 \\
(2.82 \mathrm{e}-08)\end{array}$ & $\begin{array}{c}5.60 \mathrm{e}-09 \\
(2.71 \mathrm{e}-08)\end{array}$ \\
\hline $\begin{array}{l}\text { Share of manufacturing } \\
\text { in total value, } 1860\end{array}$ & & & $\begin{array}{l}0.147 * * * \\
(0.0339)\end{array}$ & & & $\begin{array}{l}0.106^{* *} \\
(0.0496)\end{array}$ \\
\hline Constant & $\begin{array}{l}0.213 * * * \\
(0.00734)\end{array}$ & $\begin{array}{l}0.221 * * * \\
(0.00778)\end{array}$ & $\begin{array}{l}0.216^{* * *} \\
(0.00937)\end{array}$ & $\begin{array}{l}0.282 * * * \\
(0.0109)\end{array}$ & $\begin{array}{c}0.283^{* * *} \\
(0.0117)\end{array}$ & $\begin{array}{c}0.268^{* * *} \\
(0.0140)\end{array}$ \\
\hline Observations & 972 & 818 & 683 & 927 & 787 & 662 \\
\hline R-squared & 0.328 & 0.357 & 0.350 & 0.044 & 0.057 & 0.057 \\
\hline
\end{tabular}

* = Significant at the 10 percent level.

$* *$ Significant at the 5 percent level.

$* * *=$ Significant at the 1 percent level.

Notes: Standard errors in parentheses. Southern U.S. counties only. Large plantations are defined as those with more than 10 enslaved members. Large farms are defined as those above 100 acres. Cotton production is measured in bales ginned. Share of manufacturing is manufacturing's share of total value of manufacturing and farm output in 1860 .

Sources: Segregation numbers are based on authors' own calculations using the 100 percent samples of the 1880 and 1940 federal population censuses. Other variables come from the 1860 and 1880 censuses of agriculture.

in segregation over time. However, even after controlling for the share of manufacturing and all of the other county characteristics, we are left with a large, statistically significant constant in column (6), reinforcing once again that while county characteristics can explain some of the variation in levels and trends in segregation, there remains a much more general increase in segregation over time across all areas.

\section{CONCLUSION}

We have derived a new measure of segregation from the complete federal census manuscripts using the simple criterion of the race of an individual's next-door neighbors. Our measure gives a direct assessment of the likelihood of interracial interaction in residential communities. If neighbors are less likely to be of a different race than random assignment would predict then that location is more segregated than another that is closer to random assignment. Our neighbor-based measure reveals substantial heterogeneity in segregation across regions, within regions, 
and between rural and urban areas that could not be captured with existing measures focused on sorting across political units.

When using our new measure to assess change in segregation over time, we find that the United States not only became a more segregated society from 1880 to 1940, consistent with the findings of Cutler, Glaeser, and Vigdor (1999), but that this increase in segregation was far more general than previously thought. Our findings show that the likelihood of opposite-race neighbors declined precipitously in every region of the United States. The substantial rise in segregation occurred in areas with small black population shares, areas with large black population shares, areas that experienced net inflows of black residents, areas that experienced net outflows of black residents, urban areas with large populations, and rural areas with smaller populations. The traditional story of increasing segregation in urban areas in response to black migration to urban centers must be augmented with a discussion of the increasing racial segregation of rural areas and other areas that lost black residents.

Our findings complicate traditional explanations for increasing segregation as being due to blacks clustering in small areas abutting white communities (Kellogg 1977), the use of restrictive covenants (Gotham 2000), the presence of large manufacturing firms which employed blacks, or differences in transportation infrastructure, as these were all urban phenomena. The increase in rural segregation is also at odds with historical narratives which view population dynamics in rural areas as stagnant. The focus on urban segregation has neglected the fact that rural areas were segregated and, as we have discovered, became increasingly segregated over time. While there are studies that seek to look at the causal effect of black social networks in rural areas on outcomes (Chay and Munshi 2013), they use county proportions. To the extent that networks are a function of the likelihood of contact, proportions may be a noisy proxy for networks given our finding that racial proportions are relatively poorly correlated with residential segregation. Overall, the national trend in increasing segregation in the twentieth century adds a new chapter to American history.

Our measure allows us to look at a key factor behind that trendracial sorting at the household level. We found that the likelihood of a black family having an opposite-race neighbor declined by more than 15 percentage points from 1880 to 1940 , more than a 25 percent decline in the likelihood of opposite-race neighbors. Rather than being the product of black migratory patterns, regional differences in black location patterns, or white population flows out of central cities, the increase in racial sorting was quite general. Areas that both gained and lost African 
American residents saw substantial increases in racial segregation at the household level. This new fact calls for a reinterpretation of segregation trends over time and suggests that a broader range of outcomes could be related to segregation in rural and urban areas which may have persistent effects.

Our finding that segregation and its rise over the first half of the twentieth century was a truly national phenomenon occurring in both the cities people were moving to and the rural areas they left also opens new, important lines of inquiry. First, the level and change in rural segregation suggests that population sorting was strong in rural areas and could be related to a host of outcomes. Second, understanding the relationship between segregation, urbanization, and population flows will help us understand the dynamics of segregation in cities and rural communities over the twentieth century. These links have important implications for the skill mix of cities, public finance, education, inequality, health, and other measures of social well-being. The availability of complete count census data will allow researchers to explore these historical links in more detail than ever before. Third, the strong persistence of our segregation measure suggests that the roots of contemporary segregation may be more varied than previously thought. Both rural and urban areas had different levels of segregation that were highly persistent over time. This finding poses a range of questions about the impact of Jim Crow, racial violence, European immigration, internal migration, and the differences and similarities between racial segregation in rural and urban areas in the United States. The scope of segregation research is now broader with this neighbor-based measure.

\section{REFERENCES}

Agresti, Barbara. "Measuring Residential Segregation in Nineteenth Century American Cities." Sociological Methods and Research 8, no. 4 (1980): 389-99.

Almond, Douglas, Kenneth Chay, and Michael Greenstone. "Civil Rights, the War on Poverty, and Black-White Convergence in Infant Mortality in the Rural South and Mississippi." MIT Department of Economics Working Paper, Cambridge, MA, 2006.

Alston, Lee, and Joseph Ferrie. "Paternalism in Agricultural Labor Contracts in the U.S. South: Implications for the Growth of the Welfare State." American Economic Review 83, no. 4 (1993): 852-76.

Ananat, Elizabeth. "The Wrong Side(s) of the Tracks: The Causal Effects of Racial Segregation on Urban Poverty and Inequality." American Economic Journal Applied Economics 3, no. 2 (2011): 34-66.

Ananat, Elizabeth, and Ebonya Washington. "Segregation and Black Political Efficacy." Journal of Public Economics 93, no. 5 (2009): 807-22. 
Bayer, Patrick, Fernando Ferreira, and Robert McMillan. "A Unified Framework for Measuring Preferences for Schools and Neighborhoods." Journal of Political Economy 115, no. 4 (2007): 588-638.

Beck, E. M., and Stewart Tolnay. "The Killing Fields of the Deep South: The Market for Cotton and the Lynching of Blacks, 1882-1930." American Sociological Review 55, no. 4 (1990): 526-39.

Bobo, Lawrence, and Camille Zubrinsky. "Attitudes on Residential Integration: Perceived Status Differences, Mere In-group Preference, or Racial Prejudice?" Social Forces 74, no. 3 (1996): 883-909.

Borjas, George. "Ethnicity, Neighborhoods, and Human-Capital Externalities." American Economic Review 85, no. 3 (1995): 365-90.

Boustan, Leah Platt. "Was Postwar Suburbanization White Flight? Evidence from the Black Migration.” Quarterly Journal of Economics 125, no. 1 (2010): 417-43.

Brooks-Gunn, Jeanne, Greg Duncan, Pamela Kato Klebanov, et al. "Do Neighborhoods Influence Child and Adolescent Development?" American Journal of Sociology 99, no. 2 (1993): 353-95.

Card, David, Alexandre Mas, and Jesse Rothstein. "Tipping and the Dynamics of Segregation.” Quarterly Journal of Economics 123, no. 1 (2008): 177-218.

Carrell, Scott, Mark Hoekstra, and James West. "The Impact of Intergroup Contact on Racial Attitudes and Revealed Preferences.” NBER Working Paper No. 20940, Cambridge, MA, February 2015.

Case, Anne, and Lawrence Katz. "The Company You Keep: The Effects of Family and Neighborhood on Disadvantaged Youths.” NBER Working Paper No. 3705, Cambridge, MA, May 1991.

Chay, Kenneth, and Kaivan Munshi. "Black Networks after Emancipation." Working Paper, Brown University, Providence, RI, 2013.

Clark, W.A.V. "Residential Preferences and Neighborhood Racial Segregation: A Test of the Schelling Segregation Model.” Demography 28, no. 1 (1991): 1-19.

Collins, William, and Robert Margo. "Residential Segregation and Socioeconomic Outcomes: When Did Ghettos Go Bad?" Economics Letters 69, no. 2 (2000): 239-43.

Cutler, David, and Edward Glaeser. "Are Ghettos Good or Bad?" Quarterly Journal of Economics 112, no. 3 (1997): 827-72.

Cutler, David, Glaeser, Edward, and Vigdor, Jacob. "The Rise and Decline of the American Ghetto.” Journal of Political Economy 107, no. 3 (1999): 455-506. (2008). "When Are Ghettos Bad? Lessons from Immigrant Segregation in the United States." Journal of Urban Economics 63, no. 3 (2008): 759-74.

Echenique, Federico, and Roland Fryer. "A Measure of Segregation Based on Social Interactions." Quarterly Journal of Economics 122, no. 2 (2007): 441-85.

Farley, Reynolds, Elaine Fielding, and Maria Krysan. "The Residential Preferences of Blacks and Whites: A Four-Metropolis Analysis." Housing Policy Debate 8, no. 4 (1997): 763-800.

Fischer, Roger. "Racial Segregation in Ante Bellum New Orleans.” American Historical Review 74, no. 3 (1969): 926-37.

Gotham, Kevin. "Urban Space, Restrictive Covenants and the Origins of Racial Residential Segregation in a US City, 1900-1950.” International Journal of Urban and Regional Research 24, no. 3 (2000): 616-33.

Grigoryeva, Angelina, and Martin Ruef. "The Historical Demography of Racial Segregation.” American Sociological Review 80, no. 4 (2015): 814-42. 
Higgs, Robert. "The Boll Weevil, the Cotton Economy, and Black Migration 1910 1930." Agricultural History 50, no. 2 (1976): 335-50.

Holley, Donald. The Second Great Emancipation: The Mechanical Cotton Picker, Black Migration, and How They Shaped the Modern South. Fayetteville: University of Arkansas Press, 2000.

Hornbeck, Richard, and Suresh Naidu. "When the Levee Breaks: Black Migration and Economic Development in the American South." American Economic Review 104, no. 3 (2014): 963-90.

Kain, John. "Housing Segregation, Negro Employment, and Metropolitan Decentralization." Quarterly Journal of Economics 82, no. 2 (1968): 175-97.

Kellogg, John. "Negro Urban Clusters in the Postbellum South." Geographical Review 67, no. 2 (1977): 310-21.

Lee, Barrett, Sean Reardon, Glenn Firebaugh, et al. "Beyond the Census Tract: Patterns and Determinants of Racial Segregation at Multiple Geographic Scales.” American Sociological Review 73, no. 4 (2008): 761-91.

Lichter, Daniel, and Kenneth Johnson. "Emerging Rural Settlement Patterns and the Geographic Redistribution of America's New Immigrants.” Rural Sociology 71, no. 1 (2006): 109-31.

Lichter, Daniel, Domenico Parisi, Stephen Grice, et al. "National Estimates of Racial Segregation in Rural and Small-Town America." Demography 44, no. 3 (2007): 563-81.

Litwack, Leon. Trouble in Mind: Black Southerners in the Age of Jim Crow. New York: Alfred K Knopf, 1998.

Magnuson, Diana, and Miriam King. "Comparability of the Public Use Microdata Samples: Enumeration Procedures." Historical Methods: A Journal of Quantitative and Interdisciplinary History 28, no. 1 (1995): 27-32.

Margo, Robert. Race and Schooling in the South, 1880-1950. Chicago: University of Chicago Press, 1990.

Massey, Douglas, and Nancy Denton. "The Dimensions of Residential Segregation." Social Forces 67, no. 2 (1988): 281-315.

McMillan, H. G. Rural Credits or How to Finance the Farmer. Sioux City, IA: Farmer and Breeder, 1916.

Munshi, Kaivan. "Community Networks and the Process of Development." Journal of Economic Perspectives 28, no. 4 (2014): 49-76.

Naidu, Suresh. "Suffrage, Schooling, and Sorting in the Post-Bellum U.S. South." NBER Working Paper No. 18129, Cambridge, MA, June 2012.

Parman, John. "Good Schools Make Good Neighbors: Human Capital Spillovers in Early 20th Century Agriculture." Explorations in Economic History 49, no. 3 (2012): 316-34.

Rabinowitz, Howard. Race Relations in the Urban South, 1865-1890. Athens, GA: University of Georgia Press Athens, 1996.

Ramcharan, Rodney. "Inequality and Redistribution: Evidence from U.S. Counties and States, 1890-1930.” Review of Economics and Statistics 92, no. 4 (2010): 729-44.

Ransom, Roger, and Richard Sutch. One Kind of Freedom: The Economic Consequences of Emancipation. New York: Cambridge University Press, 2001.

Reardon, Sean, Stephen Matthews, David O'Sullivan, et al. “The Geographic Scale of Metropolitan Racial Segregation." Demography 45, no. 3 (2008): 489-514.

Reardon, Sean, and David O'Sullivan. "Measures of Spatial Segregation." Sociological Methodology 34, no. 1 (2004): 121-62. 
Rhode, Paul, and Koleman Strumpf. "Assessing the Importance of Tiebout Sorting: Local Heterogeneity from 1850 to 1900." American Economic Review 93, no. 4 (2003): 1648-77.

Ruggles, Steven, Katie Genadek, Josiah Grover, et al. Integrated Public Use Microdata Series Sample of the 1880 Federal Census. Accessed through usa.ipums.org/usa/., 2009.

Schelling, Thomas. "Models of Segregation.” American Economic Review 59, no. 2 (1969): 488-93.

- "Dynamic Models of Segregation.” Journal of Mathematical Sociology 1, no. 2 (1971): 143-86.

Shertzer, Allison, and Randall Walsh. "Racial Sorting and the Emergence of Segregation in American Cities.” NBER Working Paper No. 22077, Cambridge, MA, March 2016.

Spain, Daphne. "Race Relations and Residential Segregation in New Orleans: Two Centuries of Paradox." Annals of the American Academy of Political and Social Science 441, no. 1 (1979): 82-96.

Sumpter, Amy. "Segregation of the Free People of Color and the Construction of Race in Antebellum New Orleans." Southeastern Geographer 48, no. 1 (2008): 19-37.

Taylor, Charles. "Rural Credits." The Weekly Underwriter 93, no. 24 (1915): 725-26.

Tolnay, Stewart, and E. M. Beck. "Racial Violence and Black Migration in the American South 1910 to 1930." American Sociological Review 57, no. 1 (1992): 103-16.

Troesken, Werner. "The Limits of Jim Crow: Race and the Provision of Water and Sewerage Services in American Cities, 1880-1925." Journal of Economic History 62, no. 3 (2002): 734-72.

U.S. Department of Commerce. Sixteenth Census of the United States: 1940, Section 3, Part 2: Agriculture, Size of Farms. Washington, DC: GPO, 1943.

U.S. Department of Commerce. Measuring America: The Decennial Censuses from 1790 to 2000. Washington, DC: GPO, 2002.

U.S. Department of the Interior. Tenth Census of the United States: Instructions to U.S. Marshalls. Washington, DC: GPO, 1880, accessed through https://usa.ipums.org/ usa/voliii/inst1880.shtml.

U.S. Senate Committee on Banking and Currency. Agricultural Credit - Land-Mortgage or Long-Term Credit: Report of the United States Commission to Investigate Cooperative Land-Mortgage Banks, Cooperative Rural Credit Unions, and Similar Organizations and Institutions Devoting Their Attention to the Promotion of Agriculture and the Betterment of Rural Conditions. Washington, DC: GPO, 1914.

Williams, Jr., Robin. "The Reduction of Intergroup Tensions: A Survey of Research on Problems of Ethnic, Racial, and Religious Group Relations." Social Science Research Council Bulletin 57, no. 11 (1947): 153.

Wright, Gavin. Old South, New South: Revolutions in the Southern Economy Since the Civil War. New York: Basic Books, 1986.

Zubrinsky, Camille, and Lawrence Bobo. "Prismatic Metropolis: Race and Residential Segregation in the City of the Angels." Social Science Research 25, no. 4 (1996): 335-74. 